Review Article

\title{
Tropical Diseases
}

NILIMA KSHIRSAGAR*

National Chair Clinical Pharmacology, ICMR, Delhi, Former Dean Director MEH, GSMC, KEM Hospital, Mumbai, India, Ag Vice-Chancellor MUHS, Nasik, India

(Received on 01 August 2017; Accepted on 10 October 2017)

\begin{abstract}
Tropical diseases encompass all diseases that occur solely or principally in the tropics. In practice the term is often taken to refer to infectious diseases that thrive in hot humid conditions. Tropical diseases affect large population, are potentially preventable, affect economically backward communities and are neglected.

In past two decades with funding from national and global agencies, new drugs, vaccines, diagnostics have been developed tested and some of the diseases are identified for elimination.

This review focuses on diseases relevant to India viz., malaria, leishmaniasis, lymphatic filariasis and dengue and work done on epidemiology, policy, diagnostic tests, drug resistance, clinical trials, pharmacovigilance, new drugs and vaccines, in India.

Significant contributions have been made by India by carrying out clinical trials on new drugs, developing treatment guidelines for control and elimination of malaria (resistant falciparum, $P$. vivax relapse) leishmaniasis (liposomal amphotericin, combination with miltefosine for VL and PKDL) and filariasis (mass drug administration of DEC and ABZ).

Liposomal amphotericin developed in India has been evaluated clinically and marketed for visceral leshmaniasis. A novel trioxane antimalarial developed by CDRI has undergone phase I study. Arterolane piperaquine developed in India is marketed for falciparum and vivax malaria. Another drug for dengue is undergoing clinical trials. Several in vitro and preclinical studies on medicinal plants, synthetic chemicals, nanoparticles have also been carried out and await further development.
\end{abstract}

Keywords: Epidemiology; Drug Resistance; Clinical Trials; Drug Development; New Drugs

\section{Introduction}

Tropical diseases encompass all diseases that occur solely or principally in the tropics. In practice the term is often taken to refer to infectious diseases that thrive in hot humid conditions, such as malaria, leishmaniasis, schistosomiasis, onchocerciasis, lymphatic filariasis, chagas disease, African frypanosomiasis, and dengue (WHO Health topics, Tropical diseases).

Tropical diseases affect large population and are potentially preventable, affect economically backward communities, and are neglected. In the past few decades with the initiative and funding from WHO, Governments and other donors, new drugs, vaccines, diagnostic tools have been developed and immunological responses investigated. Leishmaniasis, filariasis and malaria have been identified for elimination.

In this update, tropical diseases relevant to Indiaviz., malaria, leishmaniasis, lymphatic filariasis and dengue are covered.

\section{Methodology}

For preparing this manuscript PubMed and Google scholar were searched for articles with key words tropical disease, specific disease, pharmacology and India, with filter applied for year of publication from 2012-2017. 
PubMed and Google scholar search gave initial hit publications, titles of which were perused to get potentially eligible, abstracts of which were seen to finally get publication of interest

Initial hits- 31,220

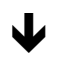

Potentially eligible-592

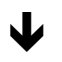

Finally included-173

Most of the publications are from research institutes, few are from medical and pharmacy colleges.

Publications for each disease are grouped according to publications on epidemiology, incidence, prevalence, policy, susceptibility to disease, diagnostic and prognostic tests, drug resistance, clinical trials, pharmacovigilance, prescribing practices, quality of marketed products, new drugs and vaccines.

To achieve control and elimination, besides chemotherapy, chemoprevention and immunological approaches, concerted efforts to control vector and protect subjects from insect bite are needed simultaneously. Work done in India for vector control and personal protection is not covered in this review.

\section{Malaria}

\section{Epidemiology, Incidence, Prevalence and Policy}

$P$. vivax has been the focus of attention due to its relapsing nature and recent observations about the complications it produces.

The epidemiology of $P$. vivax malaria, response to treatment of acute attack with chloroquine and preventing relapse with primaquine and bulaquine has been reviewed (Anvikar et al., 2016). As P. vivax cannot be reliably differentiated from recrudescence or reinfection, recurrence rates were assessed. There is variation in relapse patterns both across and within states. Strains of differing patterns of relapse can coexist, complicating transmission and control measures. For e.g., in Delhi, Group I tropical type, is most common with relapse between 1month and 3 month, also present are Group II and III (temperate) types with relapse between 3-5 and 6-7 months respectively. In Mumbai the relapse pattern is predominantly Group I tropical type.

Choloroquine resistance was sporadically reported but mostly there is $100 \%$ response. G6PD deficiency varies from absent to $27.1 \%$ among Angami Naga tribe. Multiple G6PD genotypes including severe variant G6PD Mediterranean exist, though there are only few reports of acute haemolytic anaemia (Anvikar et al., 2016).

Roy et at applied a $P$. vivax transmission model to surveillance data from a semiarid region in Northwest India. The results quantify the striking dependence of $P$. vivax on relapses for its survival supporting the feasibility of regional elimination using antirelapse treatment and emphasize need for replacing primaquine. (Roy et al., 2013)

Jain studied severe $P$. vivax malaria in tertiary healthcare facility in Jabalpur. Severe vivax was found in $11 \%$ out of 198 vivax cases, cerebral malaria and seizure, respiratory distress, severe anaemia each seen in $32 \%$ cases (Jain et al., 2013).

In prospective observational study in referral hospital in northern India, from Jan, 2012-Dec, 2012, clinical features of $P$. vivax were similar to $P$. falciparum, two patients died of cerebral malaria and ARDS. Children were treated with IV artesunate followed by artemethar-lumefantrine. Microscopy and PLDH based rapid diagnostic test (RDT) was used for diagnosing malaria (Gehlawat et al., 2013)

Out of 110 patients of $P$. vivax admitted in medical college hospitals in Chandigarh and Gujarat 19 had severe disease, there was wide variation in treatment given. All patients survived, one child of cerebral malaria had sequale (Singh et al., 2013).

The antimalarial policy in India was reviewed. Various unresolved challenges in the use of Artemisinin Combination Therapy (ACT), gametocytocidal and antirelapse use of primaquine, and preventing malaria during pregnancy were pointed out (Anvikar et al., 2014).

An analysis of data from 21 therapeutic efficacy trials done in India during 2009-2010 showed that P. falciparum gametocytemia was present in $18 \%$ of patients and contribute substantially to the reservoir for potential transmission (Shah et al., 2013). 
Artesunate + Sulfadoxinepyrimethamine (AS+SP) treatment failure was found to be widespread in Northeast India. Based on these results Artemether+Lumefantrine were selected for subnational drug policy for India (Mishra et al., 2014).

A state level analysis of NVBDCP data showed that ten states/UT with $30 \%$ or more tribal population comprising only $3 \%$ of total population, contributed to $14 \%$ of total malaria.

Districts with $30 \%$ or more tribal population comprising of about $8 \%$ country's population contributed to $46 \%$ of total cases, $70 \%$ falciparum and $47 \%$ malarial deaths in the country (Sharma et al., 2015).

Pathak et al. noted in Mumbai and Rourkela region, clinical malaria exhibited an adult male bias, which was not seen in children $\leq 10$ year and discussed possible roles of sex hormone, vector exposure, coinfections and other factors in this enhanced susceptibility of males (Pathak et al., 2012).

Jha studied human mannose binding lectin encoded by the MBL 2 gene variation and malaria susceptibility in Indian population and found that MBL $2 *$ LXPA increases malaria risk while MBL $2 *$ LXPA haplotypes confers protection (Jha et al., 2014).

The complement receptor 1 variant in severe malaria (SM) has been studied (Panda et al., 2012) and it was concluded that the homozygous polymorphisms of CR1 intron 27 and exon 22 (TT and GG) and alleles ( $\mathrm{T}$ and $\mathrm{G}$ ) that are associated with low expression of CR 1 on red blood cells conferred significant protection against cerebral malaria (CM), multiorgan dysfunction (MOD) and malarial deaths. Combined analysis showed significant association of blood group B/ intron 27-AA/exon 22AA with susceptibility to SM (CM and MOD) (Panda et al., 2012).

Individuals infected with $P$. falciparum and healthy controls were studied and significant role for GSTM 1 deletion in complicated malaria (ODDs. ratio 3.8, 1.9-7.4) Polymorphism in GSTP 1, SOD1 and CAT gene was found may be associated with malaria susceptibility, whereas SOD 3 polymorphism may play a role in malarial resistance (Fernandes et al., 2015).

The challenges in tackling malaria problem has been reviewed (Bharti and Ganguly, 2013). They emphasized that to achieve early case detection, diagnosis and prompt treatment (EDPT) rapid diagnostic tests of high sensitivity, specificity are needed.

There is also need to tackle issue of illegal manufacturing and cross border trafficking of fake or counterfeit drugs with inter country collaboration, use of pharmacovigilance and biochemical tests like GPHF- Minilab® dye test Kit developed by the Global Pharma Health fund for checking the quality of antimalarials such as artesunate (Bharti and Ganguly 2013).

Clinical profile and management of malaria in pediatric age group has been studied (Nayak et al. 2014). In a tertiary care hospital in Manglore 0-5 years age were more affected and $P$. vivax was major parasite type (Nayak et al., 2014).

\section{Diagnostic Tools and Pathogenesis}

Singh evaluated in the field and noted that Rapid Diagnostic tests (RDTs) are useful even at high temperature but quality should be regulated and monitored closely (Singh et al., 2013).

Sri Krishna and others showed that in 8 malaria endemic states in India, mixed plasmodium spp. infections were detected by PCR in $17.4 \%$ of blood samples in which microscopy had shown to contain only P. falciparum. The quality of microscopy needs to improve (Krishna et al., 2015).

Patients with acute undifferentiated fever were studied (Hanshuus et al., 2016) in seven secondary community level hospitals and was PCR positive in $19 \%$ cases of which P. falciparum and $P$. vivax and mixed infection was $46 \%, 38 \%$, and $11 \%$ respectively. Microscopy sensitivity was $29 \%$, specificity $98 \%$, RDT sensitivity was $24 \%$ and specificity $99 \%$ (Hanshuus et al., 2016).

Real time micro PCR point of care device developed by Bigtec lab. Banglore has limit of sensitivity of $<5$ parasites $/ \mu$, sensitivity $99 \%$. It was claimed to be suitable for diagnosis, active surveillance and epidemiological intervention (Nair et al., 2016).

The results of study by Sahu showed that compared to microscopy ParaHIT-f had sensitivity 
$63.6 \%$ specificity $98.9 \%$. Its sensitivity was $47.8 \%$ at low parasitaemia of 4-40 parasites/ $\mu$ (Sahu et al., 2015).

Sahu et al. summarized current understanding of cerebral malaria pathogenesis, compiled an array of new biomarkers and tools available for diagnosis and research and described emerging therapeutic approaches to tackle this pathology effectively (Sahu et al., 2015).

Das et al. studied genotyping of $P$. vivax by minisatellite marker and showed that CH1 T1 M13779 can be a potential minisatellite marker for differentiating relapse and new infection (Das et al., 2016).

\section{Drug Resistance}

A systematic review of antimalarial drug resistance of P. falciparum in India, changes over time and space showed the increase in chloroquine resistance over the years and also geographical spread.

Sulfadoxine pyrimethamine resistance increased from $7.7 \%$ during $1984-96$ period to $25.9 \%$ in 1997 2007, most studies were done in north eastern states and Arunachal Pradesh on the Chinese Burmese borders had the highest rate of treatment failure. This is very relevant to monitoring and policy for considering the effectiveness of treatment with artesunate plus sulfadoxine pyrimethamine which is the recommended ACT in the National program (Shah et al. 2011).

Amit Kumar genotyped 173 field isolates and found rise in resistant SP (sulphadoxinepyrimethamine) alleles from very low frequencies in 1994 to steady rise in year 2000 and maintaining this trend in year 2013, even after change in malaria treatment policy (Kumar et al., 2015).

P. falciparum field isolates in Ujjain Madhya Pradesh had sulphapyrimethamine resistance associated pfdhfr $108 \mathrm{~N}$ and 59R alleles in $96 \%$ and $90 \%$ and pfdhps $437 \mathrm{G}$ in $9 \%$, double mutant in $82 \%$, triple mutant in $8 \%$, chloroquine resistance associated pfcrt 76T in 94\%. pfmdrl S 1034+N 1042+D1246 in $97 \%$ samples. Efficacy of chloroquine was poor, and there is reduced susceptibility to SP (Pathak et al., 2014).
Drug resistance genes dihydrofolate reductase and dihydropteroate synthase in $P$. falciparum had double mutations in low transmission area while upto sextuple mutation were present in high transmission area in various states (Sharma et al., 2015).

Mutation in PfK-13 in strongly linked to artemisinin resistance. In 384 samples (from an efficacy study) PCR amplified and sequenced from codon 427 to 727 , nonsynonymous mutations were found in 4 patients from north-eastern states but this did not correlate with treatment failure (Mishra et al., 2015).

Gupta et al. studied ABCB1membrane transport genes that code for P-glycoprotein and noted that multiple mechanisms such as genetic and epigenetic variations within a key gene may play a role in malarial susceptibility and response to antimalarial drugs in the population (Gupta et al., 2017).

\section{Clinical Trials, Observational Studies, Pharmacokinetics, Pharmacovigilance}

Clinical trials to evaluate efficacy, safety, pharmacokinetics of ACT and of different doses of primaquine have been carried out in different parts of the country.

Data on patients in primary health centres is sparse.

Response to a standard doses of chloroquine, primaquine $210 \mathrm{mg}$ over 14 days was studied in $P$. vivax cases in primary health centres in Karnataka and cases were followed up for 28 days. $3 \%$ had G6PD deficiency ( $<30 \%$ normal mean activity) They received primaquine $45 \mathrm{mg}$ once a week, one patient got dark brown urination which subsided on discontinuating primaquine. All patients showed adequate clinical and parasitological response. Nested PCR showed $28 \%$ cases were mixed vivax and falciparum (Saravu et al., 2016).

To explore use of azithromycin (AZ) and chloroquine (CQ), a double blind, randomized, noninferiority study comparing AZ 1gm+CQ 600mg daily for 3 days or CQ+ sulfadoxine pyrimethamine (SP), was carried out in adult uncomplicated falciparum malaria patients. Parasite clearance rate was $84 \%$ with AZ CQ and $94 \%$ with CQ SP respectively (Kshirsagar et al., 2017 accepted). 
A comparison of artesunate amodiaquine (ASAQ) fixed dose combination with amodiaquine (AQ) for treatment of $P$. falciparum malaria in patients aged 6 months- 60 years of age showed PCR corrected cure rate in intent to treatment population to be $97.51 \%$ in ASAQ and $88.65 \%$ in AQ arm. There were 2 early treatment failures in AQ arm. (Anvikar et al., 2012)

In a Phase II multicentric open label study in children aged 6 months to 12 years with acute uncomplicated P. falciparum, efficacy and safety of fixed dose combination of arterolane maleate and piperaquine phosphate dispersible tablets was studied. PCR corrected adequate clinical and parasitological response was achieved in $100 \%$ of cases with fever clearance time and parasitological clearance time being $10 \mathrm{hr}$. and $24 \mathrm{hr}$. respectively. Most frequent adverse events (AES) were vomiting which was mild to moderate and resolved without sequalae. No changes in QT prolongation were seen (Toure et al., 2015).

In Phase 3 double blind randomized study of arterolane maleate piperaquine phosphate $(\mathrm{AM}+\mathrm{PQP})$ vs artemether-lumefantrine (AL) for P. falciparum in adolescent and adult patients in Asia and Africa, $\mathrm{AM}+\mathrm{PQP}$ showed comparable safety and efficacy to AL with high clinical and parasitological response and rapid parasitological clearance (Toure et al., 2016).

Study for therapeutic efficacy of artemether lumefantrine for treatment of falciparum malaria from three highly malarious states in malaria patients, had one late clinical failure and two late parasitological failures (Bharti et al., 2016).

A single ascending dose safety and pharmacokinetic study of 97/78 a novel trioxane developed by CDRI was carried out in healthy volunteer. It was well tolerated, t 1 1/2, MRT, AUCof the active metabolite was calculated and now further studies are awaited (Shafiq et al., 2014).

In 2009-2010 prospective study in 25 sentinel sites $98.8 \%$ efficacy for AS+SP was noted. Double mutation in $d h f r$ was found in $68.4 \%$ genotyped isolate. A daily dose of $\mathrm{AS}<3 \mathrm{mg} / \mathrm{kg}$, age less than 5 and fever at enrolment was associated with increased risk of failure. Chloroquine was $100 \%$ effective in $P$. vivax
(Mishra et al., 2012).

In Jalpalguri district significant failure of ASSP was noted with $p f d h f r, \mathrm{I}(51) \mathrm{R}(59) \mathrm{N}(108)$ and $p f d h p s$ G(437) and/or E(540) mutation (Saha et al., 2012).

Rajgor studied antirelapse efficacy of various primaquine regimens for $\mathrm{P}$. vivax in Mumbai and found that recurrence rate was $16.39,8.07,10.07,6.62$ per cent in control (no primaquine), $15 \mathrm{mg} /$ day for 14 days, $30 \mathrm{mg} /$ day 7 days, and $30 \mathrm{mg} /$ day 14 days regimen. The concordance between different methods viz month of recurrence and PCR RFLP and PCR sequencing for distinguishing relapse from re-infection was low. Probable resistance to PQ warrants continuous monitoring and caution in interpreting results of reinfection, relapse. (Rajgor et al., 2014)

Efficacy of 14 days PQ regimen $(0.25 \mathrm{mg} / \mathrm{kg} /$ day) in adult with 15 months long follow up was studied in Udupi district. Of 144 participants, $24.6 \%$ got recurrence with median duration of recurrence 3.1 months (1.2-15.1 months). Patients with history of $P$. vivax malaria had higher risk of recurrence (Kumar et al., 2016).

In a multicentric (one centre India) double blind $2 \mathrm{~b}$ study of tafenoquine, antihypnozoite efficacy was evident for reduction in homologous recurrence of P.vivax but not heterologous recurrence (Beck et al., 2016).

Therapeutic in vivo efficacy of chloroquine alone or in combination with primaquine against $P$. vivax malaria in Kolkata, West Bengal, India and polymorphism of pvmdr1 and pvcrt 0 genes. Y976 F mutation was not detected in any isolate. pvmdrl gene had 8 non-synonymous mutation B which were new. Chloroquine was effective though day 3 positivity was observed in 5.3\% cases (Ganguly et al., 2013).

Valecha studied arterolane piperaquine vs chloroquine in acute uncomplicated $P$. vivax in a phase III, multicentric open label study and found comparable efficacy (Valecha et al., 2016).

Population pharmacokinetics of mefloquine administered as a fixed dose combination of artesunate mefloquine in Indian patients for the treatment of acute complicated P. falciparum malaria was similar to Thai patients (Jullien et al., 2014). 
Lumefantrine concentration and treatment outcome in P. falciparum cases in Orissa treated with artemisinin lumefantrine was studied. One hundred per cent patients had adequate clinical and parasitological response despite high inter individual variation in lumefantrine concentration (Valecha et al., 2012).

Kadam studied pharmacokinetics of chloroquine in malnourished children, compared with normally nourished children with malaria and observed that there was wide inter individual variability in the levels of drug and metabolite but the difference between groups was not significant (Kadam et al., 2016).

500 patients of malaria were studied and it was noted that nearly half complained of ADR, though there was no serious ADR (Belhekar et al., 2012).

ADR reporting beliefs of healthcare professionals were assessed and compared and it was noted the need for specific targeted in service education with hands on training on ADR monitoring and reporting to boost real time pharmacovigilance in India was noted (Gupta et al., 2014).

\section{Targets, New Drugs, Vaccines, Mechanism of Action}

Various plants from traditional and tribal medicine, synthetic chemicals and drug delivery systems have been studied. Targets for vaccines and for developing new drugs have also been investigated. Animal model for Acute Respiratory Distress Syndrome has been developed and effect of surfactants tested (Hagawane et al., 2016).

Aqueous extract of Traditional Plant-based Malaria Prophylactic drug 74, given twice a week for 14 weeks compared to control (no drug) group had significantly fewer cases of malaria (12.3\% compared to $26.6 \%$ ) (Nagendrappa et al., 2017).

Dry rind of Punica granatum was shown to have effect on hemoprotozoa and also antiinflammatory action (Bhattacharya et al., 2013).

Traditional medicines used against fever were studied and promising antiplasmodial activity in Aegle marmelos, Lantana camara, Leucas aspera, Momordica charantia, Phyllanthus amarus, Piper nigrum was observed (Kamaraj et al., 2012).
Nine medicinal plants used by Karens of Andaman Nicobar Islands were investigated and $Z$. spectabilis, S. wallichiana, C. pulcherrima and Amomum sp. demonstrated significant antimalarial activity with no toxicity on erythrocytes (Chander $e t$ al., 2015).

Chander also found antimalarial activity in methanolic extract of $J$. syringi folium, $D$. andamanica, $C$. indicum, $P$. tithymaloides used traditionally by Nicobarese tribes (Chander et al., 2016).

Clinical activity of $N$. arbor tristis was studied and the effect of the paste of 5 fresh leaves, given thrice a day for a week in twenty patients was evaluated.

$N$. arbor tristis showed disease modifying activity, early clinical recovery, decline in TNF-á and a gradual parasite clearance (Godse et al., 2016).

Kumari showed that Nyctanthes arbor tristis (Harshringar) leaf extract and RPHPLC purified fractions had promising activity against chloroquine sensitive and chloroquine resistant strains (Kumari et al., 2012).

Antimalarial activity of ethanolic bark extract of A. lebbeck against chloroquine resistant and sensitive strains was tested and high selective index and ED ${ }_{50}$ of $<100 \mathrm{mg} / \mathrm{kg}$ against $P$. berghei was found (Kalia et al., 2015).

It was found that ethanolic extract of $O$. sanctum had significant activity against $P$. falciparum (Inbaneson et al., 2012).

A literature search was done and Vaidya/Hakim and lay people were interviewed and it was seen that 51 plants belonging to 27 families, plant root decoction are mostly used. Most popular plants are Adhatoda vasica, Cassia fistula and Swertia Chirata (Qayum et al., 2016).

Aminake synthesized hybrid molecules with covalent fusion of azidothymidine (AZT) and dihydroartemisinin (DHA) tetraoxane or a 4 aminoquinoline derivative and found antiplasmodial activity and activity against HIV in compound 7 , but it is metabolized by $\mathrm{O}$-dealkylation hence inactive in mice (Aminake et al., 2012). 
Artemether Lumefantrine nanostructured lipid carriers for oral malaria therapy was studied and enhanced efficacy at $1 / 5$ the standard dose and dosing frequency daily instead of twice a day in mouse model was found (Prabhu et al., 2016).

Goyal reviewed essential redox active processes and their components in malaria parasite and enlisted currently used redox-active antimalarials, their mode of action and pharmacotherapeutic implications (Goyal et al., 2012).

Potential drug targets in malarial parasite were reviewed (Arora and Banerjee, 2012).

Genetic variation in the $P$. falciparum circumsporozoite protein in India and its relevance to RTS, S malaria Vaccine was studied. Genetic diversity in samples collected over 5 year prospectively was studied. For RTS, S malaria vaccine candidate, naturally occurring polymorphism at the vaccine candidate loci are critical determinants of efficacy. The study provides an insight into it (Zeeshan et al., 2012).

The Duffy (FY) antigens act as receptors for chemokines as well as for $P$. vivax to invade RBCs. Occurrence of $\mathrm{FY}^{*} \mathrm{~A}$ allele is correlated with decreased susceptibility to $P$. vivax. Results of this study by Chittoria show the correlation with $\mathrm{FY} * \mathrm{~A}$ and role of natural selection (Chittoria et al., 2012).

Deletion of asparagine synthetase delays asexual and liver stage development as parasite life cycle has an absolute requirement for asparagine which could be targeted to prevent malaria transmission and liver infection (Nagaraj et al., 2015).

Thus it is seen that investigators have identified several plants with potential for antimalarial activity. What is needed is investigating effect of purified characterized extracts (phytopharmaceutical) or active molecules from the plants and testing activity on resistant strains and for anti relapse activity.

\section{Conclusion and Way Forward}

Clinical studies done in India have been of considerable use for policy making and individual patient care. e.g., artemether, lumefantrine was recommended in Northeast India based on widespread ASSP treatment failure observed. Epidemiological studies have highlighted the burden of malaria in tribal population resulting in policy of focusing on malaria in tribal region; studies on $P$. vivax have highlighted the geographical variation in relapses, ethnic variation in G6PD deficiency, genotypes and that $P$. vivax can present with severe manifestations.

Studies on efficacy of different doses of primaquine were useful to recommend National policy of 14 day treatment with primaquine. Methodological issue of differentiating relapse from re-infection has been taken up in some studies but it continues to pose a challenge. Changes in resistance pattern in $\mathrm{P}$. falciparum malaria over time and geographical areas has been well demonstrated through clinical and genetic studies and is a warning to avoid overuse and irrational use of antimalarials.

Work on drug development especially from plant sources holds promise. We need drugs which are effective against artemisinin resistant strains of $P$. falciparum, alternative to primaquine, that is safe in G6PD deficiency and effective with short course. Complicated/severe malaria can be avoided by early diagnosis and treatment. Hence sensitive, specific, point of care diagnostic tests are needed. Severe malaria still has high mortality and research into pathogenesis and drugs that can be used to treat complication of severe malaria like ARDS (Acute Respiratory Distress Syndrome) are needed.

\section{Leishmaniasis}

\section{Incidence Prevalence Policy}

Kala Azar (Visceral Leishmaniasis) VL is a major public health problem in four states of India. The disease has been targeted for elimination by 2017 . Elimination is defined as reduction in the annual incidence of Kala Azar to less than 1 case per 10,000 populations at the sub district level.

Over time, cases have shown a decline from 24212 cases with 93 deaths in 2009 to 8223 cases and nine deaths in 2015.

Sodium stibogluconate was main drug in the National program in 1990's. However there was increasing resistance. Miltefosine an oral drug was introduced. Amphotericin though very effective was toxic. Liposomal amphotericin with considerably reduced toxicity was introduced. 
There are several challenges in control and elimination of VL such as rational use of drugs and understanding Post Kala Azar Dermal Leishmaniasis (PKDL).

Predictors from three transmission models were compared and it was concluded from all models that L. donovani transmission will continue after 2020 and surveillance and control measures need to remain in place until longer term aim of breaking transmission is attained (Rutte et al., 2017).

To halt increasing unresponsiveness to drugs it has been highlighted that various steps need to be taken such as rational dosing, and duration, identify markers of resistance, use of effective combinations, immunotherapy, management of HIV/VL confection and PKDL (Sundar et al., 2014).

The need for pharmacovigilance and economic alternatives to ambisome has been commented upon (Kshirsagar, 2014 a). Different liposomal formulations of amphotericin vary in efficacy and safety due to difference in composition, particle size and manufacturing process. There is need for preclinical animal pharmacokinetic, safety, efficacy and clinical data besides pharmaceutical characterisation for liposomal formulation which may be similar but not same to regulatory approved marketed products like ambisome or fungisome (Kshirsagar, 2014 b).

The clinical, epidemiological, parasitological and immunological perspective of PKDL has been reviewed and hypotheses developed relating to role of antimonial drugs, UV induced skin damage, reinfection, organ specific failure of memory $\mathrm{T}$ cell response and genetic susceptibility of host, to explain development of PKDL (Mukhopadhyay et al., 2014).

Clinically suspected cases of PKDL were investigated with $r k-39$ strip, microscopy and $P C R / q$ PCR. 20\% of cases of PKDL had no history of VL. Diagnostic sensitivity was $32-36 \%$ with microscopy, 96-100\% with $P C R / q$ PCR. Compliance to treatment was $85 \%$ with miltefosine and $15 \%$ with antimonial. Relapse rate with miltefosine was $13.2 \%$ (Ramesh et al., 2015a).

Cutaneous Leishmaniasis is endemic in Bikaner region situated in Thar Desert in Rajasthan. Clinical features of preschool children (0-5 year of age) has been described. L. tropica is usual causative species. Intralegional sodium stibogluconate is well tolerated. Other therapies that are effective are oral rifampicin, oral dapsone, radio frequency, heat therapy and combination of three therapies (Agarwal et al., 2014).

\section{Diagnostic, Prognostic Tests and Tools}

The current status and challenges in various diagnostic tools for diagnosis of VL have been discussed and their applications assessed in resource poor settings (Singh and Sundhar, 2015).

In one study, serological test, DTH or conventional PCR or quantitative PCR have been used to detect asymptomatic or early infection and as predictor of progression to symptomatic disease, $34.7 \%$ of 1469 healthy individuals living in endemic area were PCR positive. There was poor agreement with serology testing and in subjects who developed symptomatic VL after 12 months (Sudarshan et al., 2014).

Singh evaluated $r k-39$ strip and with some modification it showed sensitivity of $100 \%$ in serum while in urine, it was $96 \%$ with specificity $100 \%$ (Singh et al., 2013).

rKE 16 antigen based rapid test flow through test (KEFT) was comparable to $r k-39$ and better than lateral flow test (KELF) (Vaish et al., 2012).

\section{Drug Resistance}

Two patients of VL were studied, whose blood buffy coat grew L. donovani. Both isolates had good $\mathrm{IC}_{50}$ value for amphotericin $(0.07,0.1 \mu \mathrm{g} / \mathrm{ml})$, one isolate was refractory to antimony $\mathrm{sb}^{\mathrm{III}}$ with $\mathrm{IC}_{50}$ more than $200 \mu \mathrm{m}$, one had $36.7 \mu \mathrm{m}$, but both had miltefosine $\mathrm{IC}_{50}>100 \mu \mathrm{m}, 10$ fold higher than standard strain DD8 with $\mathrm{IC}_{50} 6.8 \mu \mathrm{m}$. Genetic analysis showed $\mathrm{SNP}_{354} \mathrm{Tyr}$ $\leftrightarrow$ Phe and ${ }_{1078}$ Phe $\leftrightarrow$ Tyr in LdMT gene (Srivastava et al., 2017).

In J 774A.1 macrophage cell line, increased tolerance with high $\mathrm{ED}_{90}$ value for miltefosine and paromomycin in isolates from a patient from high endemic region was noted (Prajapati et al., 2012a).

It was found that in vitro susceptibility of VL isolates from relapsed VL and PKDL cases had lower susceptibility than pre-treatment isolates, PKDL 
isolates were more tolerant to miltefosine (MIL) compared to VL isolates. All were uniformly susceptible to paromomycin. Mutations in the LdMT and LDRos3 genes that previously correlated with experimental resistance to MIL were not present for the field isolates (Bhandari et al., 2012).

Deep studied L. donavani pre-treatment (LdPreTx) isolates and post treatment isolates (LdRelapse) from VL and PKDL patients that relapsed and parasites made experimentally resistant to MIL (LdM30) and found higher $\mathrm{IC}_{50}$ and lower MIL accumulation in LdRelapse parasites compared to LdPreTx (Deep et al., 2017).

Functional studies were carried out to determine activity of the efflux pumps in antimonial resistant clinical isolate from India. Molecular characterization of thiol levels was also carried out and was found over expression of gene coding of Y glutamylcysteine synthetase was found thereby establishing that thiols are key determinants was found of antimonial resistance. $\mathrm{Sb}^{\mathrm{III}} /$ thiol conjugates can be sequestered by $\mathrm{ABC}$ transporter multidrug resistance protein $\mathrm{A}$ (MRPA) into intracellular organelles and pumped out by an uncharacterized transporter (Singh et al., 2014).

Mitogen activated protein kinase 1 single allele replacement mutant exhibited increased resistance to $\mathrm{sb}^{\mathrm{III}}$, it negatively regulates the expression of pglycoprotein type efflux pump in the parasite. The decrease in efflux pump activity with an increase in LdMAPK1 activity may result in increased antimony accumulation in the parasite, making it more vulnerable to the drug (Garg and Goyal, 2015).

\section{Clinical Trials and Observational Studies}

A 2007 observational cohort study in Bihar of 251 patients with VL, treated with $20 \mathrm{mg} / \mathrm{kg}$ IV. Ambisome demonstrated $98 \%$ cure rate at 6 month between July 2007 \& Aug 2012. Medicines Sans Frontiers (MSF) and Rajendra Prasad Memorial Research Institute (RMRI), implemented a VL treatment project in Bihar. IV ambisome was given in 4 dose of $5 \mathrm{mg} / \mathrm{kg}$ over 4-40 days. The observational cohort study by Burza et al. describes 8749 patients with laboratory confirmed primary VL treated over 5 year period. 1396 were treated at primary health centre, 7189 in hospital and 164 in camps. Initial cure rate was $99.3 \%$, $0.3 \%$ defaulted $0.4 \%$ died $1.8 \%$ were HIV co- infected, $0.6 \%$ were TB co-infected. $0.1 \%$ discontinued due to allergy and $0.3 \%$ were readmitted due to PKDL.

Risk factors for late presentation were female sex, age $\geq 15$ years. Of the 984 patients treated, 827 were traced, $20(2.4 \%)$ relapsed with mean time to relapse was $9.6 \pm 3$ months (Burza et al., 2014a).

In a further study, Burza noted that $1.4 \%$ of initially cured 8537 patients relapsed with median time of relapse 10 months. Male sex, age $>5$ and $\leq 45$ year, decrease in spleen size at the time of discharge of $<0.5 \mathrm{~cm} /$ day and shorter duration of symptoms prior to seeking treatment were significantly associated with relapse (Burza et al., 2014 b).

Amongst patients treated with $20 \mathrm{mg} / \mathrm{kg}$ liposomal amphotericin (Ambisome), $0.3 \%$ had passively returned with PKDL. Median time to developing PKDL (1.2 years) was shorter compared to conventional VL treatment (Burza et al., $2014 \mathrm{c}$ ).

In 71 parasitologically proven VL patients, efficacy of miltefosine given as per NVBDCP guidelines, was $93 \%$ and no adverse effects were observed during study period (Patra et al., 2012).

Sundar studied in 567 patients effect of miltefosine and concluded that compared to phase III trial that led to registration of drug a decade ago, there is a substantial increase in failure rate of oral miltefosine for treatment of VL in India (Sundar et al., 2012).

Confirmed PKDL cases were treated with miltefosine $50 \mathrm{mg}$ twice a day for 90 days (regimen 1) or $50 \mathrm{mg}$ thrice day for 60 days (regimen 2). Of the 73 treatment completed cases, 11 cases relapsed by end of 18 months, significantly higher in regimen 2 $(31 \%)$ vs $(10.5 \%)$ in regimen 1 . Parasite load pretreatment was significantly higher in patients that relapsed. In vitro susceptibility of isolates after relapse was significantly (2 fold) lower compared to pretreatment isolates (Ramesh et al., 2015b).

Fungisome (Indian Liposomal amphotericin) $5 \mathrm{mg} / \mathrm{kg}$ daily for 2 days and $7.5 \mathrm{mg} / \mathrm{kg}$ daily for 2 days had initial cure rate of $100 \%$ at $1 \mathrm{mt}$. At $6 \mathrm{mt}$ it was $90 \%$ with $10 \mathrm{mg} / \mathrm{kg}$ and $100 \%$ with $15 \mathrm{mg} / \mathrm{kg}$. There was no SAE (Goswami et al., 2016). 
Retrospective analysis of HIV-VL co-infected cases treated between July 2012 and Sept. 2014 with $30 \mathrm{mg} / \mathrm{kg}$ IV liposomal amphotericin, given as 6 equal dose, with 14 days of $100 \mathrm{mg}$ /day oral miltefosine was carried out in 102 patients. They had all cause cumulative mortality, relapse at 18 months $16.6 \%$ and $13.9 \%$ resp. Not initiating ART and concurrent tuberculosis were independent risk factors for mortality (Mahajan et al., 2015).

\section{New Drugs and Vaccines}

Several workers have reviewed/summarized developments in the diagnosis and approaches to antileshmanisal drug discovery and development, (Bhargava and Singh, 2012), compounds isolated from various natural sources that are worth screening as anti-leishmanial drug candidates (Tiwari et al., 2017) important biochemical and enzymatic machinery that could be used as putative drug targets for antileishmanial drug (Singh et al., 2012) and successes and failures of genetically modified organisms used in vaccination (Chhajer and Ali, 2014).

Original research publications during 2012-2017 periods are described below.

Ten weeks post infection BALB/c mice were orally given hexane fraction of Artemisia Annua leaves (AAL) and seeds (AAS). There was significant reduction in parasitic burden, strong DTH response, increased $T h l$ response and induction of immunological memory. It could be an adjunct therapy for VL (Islamuddin et al., 2015).

Studies were done with CpG ODN 2006 (synthetic oligodeoxynucletide containing unmethylated cytosine phosphate guanine) $\mathrm{CpG}$ motif mimic microbial DNA and are recognised as toll-like receptors 9 on cells and stimulate innate immune response) $0.4 \mathrm{mg} / \mathrm{kg}$ single dose as free and liposomal form with or without miltefosine for 5 days in infected hamster mice was studied. The combination with liposomal form showed the best inhibition of parasite multiplication and biased Th 1 response (Shivahare et al., 2014).

Oil in water emulsion of Eugenol showed significant antileishmanial effect in vitro and when given IP daily for 10 days caused significant decrease in DTH and fall in disease associated Th2 cytokines and potentiated Thl response (Islamuddin et al., 2016).

Carbon nanotubes functionalized with amphotericin administered orally resulted in 99\% inhibition of parasite growth following 5 day course at $15 \mathrm{mg} / \mathrm{kg}$ body weight in hamster model (Prajapati et al., 2012b).

Nanoliposomal artemisinin with mean particle diameter of $83 \pm 16 \mathrm{~nm}$ reduced intracellular infection of L. donovani ex vivo and in murine model inhibited infection in liver and spleen and modulated immunity towards protective Thl type response (Want et al., 2017).

Phosphatidylcholine PC dimethyldioctadecyl ammonium bromide (DDAB) SSG was found to alleviate SSG sensitive and resistant $L$. donovani infection in BALB/c mice, probably due to better interaction with parasite membrane (Sinha et al., 2015).

Ursolic acid loaded N-octyl-chitosan surface decorated nanostructured lipid carrier system was prepared for delivery to macrophages for VL, characterised, was found to be more active than free form and in vivo study showed parasite burden could be suppressed by $98.75 \%$ (Das et al., 2017).

Alginate coated Nano capsule were prepared and loaded with doxorubicin, compared against nanoemulsion containing doxorubicin and it was found that it had better uptake greater efficacy against intramacrophagic amastigotes, better efficacy on parasite burden in leishmania infected hamster and enhanced apoptotic efficacy (Kansal et al., 2014).

A series of novel aminoquinaldine derivatives, a new class active in vitro and in vivo, when given IP and orally in BALB/c murine model with sodium antimony gluconate sensitive and resistant $L$. donovani, were investigated. PP9 and PP10 compounds were promising lead compounds with potential for treating VL with oral route (Palit et al., 2012).

Mishra has taken a target based therapeutic approach. Two isobenzofuranone compounds were synthesized and characterized in BALB/c mouse model. They showed potent antilieishmanial effect in antimony sensitive and resistant parasites and also 
induced Th 1 cytokine response (Mishra et al., 2014). They also studied a new amphiphilic formulation of amphotericin B (kalsome TM 10) and found it to be significantly safer that amphotericin B deoxycholate and was effective in mouse models (Mishra et al., 2013).

Computational and biophysical studies revealed that paromomycin/miltefosine interact with TLR9 inducing TLR9 dependent NF-KB promoter activity through MyD88 and functional maturation of DCs (Das et al., 2014).

B Nitrostyrenes compounds were found to be active in vitro (comparable to $\mathrm{AMB}$ ) against promastigotes and amastigotes (Shafi et al., 2016).

It was also noted that $2 \mathrm{NB} 2$ nitro- $\mathrm{N}$-(pyridine$2 y$ lmethyl) benzene sulphonamide was active against promastigotes and intracellular amastigotes and it also increased efficacy of amphotericin against amphotericin resistant L. donovani (Dikshit et al., 2016).

\section{Vaccines}

VL vaccine scenario has recently been reviewed. Although in recent years a large body of researchers have concentrated their efforts, only three vaccines candidates have gone for clinical trials. Killed vaccine in Brazil for immunotherapy, live attenuated vaccine for humans in Uzbekistan and one for dogs. There are half a dozen in pipeline. Leish III F failed to protect, its phase I was done in India (Srivastava et al., 2016).

rLD Sir 2RP has been studied as a vaccine candidate against VL and naive hamsters when vaccinated with it were found to resist the $L$. donovani challenge to the tune of $75 \%$ with increased in $I g G 2$ antibody level, which is indicative of Thl type of protective response (Baharia et al., 2015).

Kaur et al. examined the protective efficacy of DNA vaccine based on gp63 and Hsp 76 against murine visceral leishmaniasis. Inbred BALB/C mice were immunized s.c. twice at an interval of 3 weeks with PC DNA 3.1 (+) encoding epitopes of gp63 and Hsp 76. Immunized animals had significant reduction in parasite burden, heightened DTH response and elevated $T h 1$ cytokines and reduced $1 g G 1$ and $I L$ 10 levels (Kaur et al., 2016).

\section{Conclusion and Way Forward}

Visceral Leishmaniasis is targeted for elimination in India by 2017.

Studies done in India have contributed to the elimination program. Liposomal amphotericin developed in India has been shown to be effective in VL with 2 days treatment.

PKDL cases are considered as reservoirs hence preventing and managing them is important for the elimination program. Patients treated with liposomal amphotericin ambisome have low relapse rate and development of PKDL is low. Clinical trial on PKDL patients have shown that long duration of treatment is required with miltefosine.

Current treatments for VL and PKDL though effective are prolonged and require parenteral administration. Miltefosine treatment though oral is prolonged and development of resistance is a problem. There is need for newer drugs. As stated above there are several publications/studies on new drug development from India. However at present none seem to fit the public health requirement as suitable alternative or addition to current treatment. Studies are needed to develop products which are effective orally, requiring short duration of treatment, active against sensitive and resistant strains, safe to be administered to diseased asymptomatic carriers, PKDL cases and effective in HIV/VL co-infected cases, women and children. There is need for basic work on asymptomatic carriers, their conversion to VL, PKDL disease and diagnostics to differentiate between infected and diseased, cured and likely to relapse. Drugs that will target such conversion are needed. Clinical trials with existing drugs/combinations that will shorten treatment especially for PKDL could be an immediate short term strategy.

\section{Lymphatic Filariasis}

\section{Epidemiology, Mass Drug Administration Incidence, Prevalence, Policy}

The goal of global program to eliminate lymphatic filariasis (GPELF) launched in 2000 is to eliminate the disease as a public health problem by 2020 . The programme aims to achieve the goal by interrupting transmission through annual single dose mass drug 
administration (MDA) of albendazole (ABZ) fixed dose $400 \mathrm{mg}$ with or without diethylcarbamazine cirtrate (DEC) $6 \mathrm{mg} / \mathrm{kg}$ for 5-6 years. India contributes to nearly $1 / 3^{\text {rd }}$ of global burden of LF and a program was initiated on a pilot basis in 13 of the 250 endemic districts, implementation units (I.U.) during 1996-1997 with DEC alone and thereafter with DEC+ABZ. The program has been gradually scaled up to reach all the 250 endemic districts spread over 20 states and union territories, covering 421 of the 590 million people at risk in 2007. The impact of the program is to be monitored in at least one sentinel and one spot check site for microfilaremica (MF). It has been reported that in 192 of the 250 implementation units (IU) MF prevalence has reached $<1 \%$, the recommended threshold for proceeding with further epidemiological assessment, which is required prior to making a decision to stop or continue MDA.

Model based on empirical observations has been used and it was concluded that during 2000-2012 the mass drug administration program has made remarkable progress. A total of 6.37 billon treatments were offered and 4.45 the billon treatments consumed, 96.7 million LF cases, including 79.2 million $\mathrm{mf}$ carriers, 18.7 million hydrocele cases, and 5.49 million lymphedema cases have been prevented or cured (Ramaiah and Ottesen, 2014).

Mathematical modelling of lymphatic filaras is elimination programmes in India has been carried out to predict required duration of mass drug administration and post treatment level of infection indicators.

Using a model variant for Indian setting it was observed that the required duration of annual MDA increases with higher baseline endemicity and lower coverage. To achieve elimination in high transmission area and high infection levels, MDA must be continued longer than in low endemic communities (Jambulingam et al., 2016).

Babu et al. systematically reviewed published studies on coverage and compliance with MDA in India. They identified 36 published papers. Coverage varied from 48.8-98.8\%, compliance from 20.8-93.7\% and there were potentially correctable causes (Babu and Babu, 2014).

The effect of eight rounds of mass drug administration has been studied in primary health centres in Thanjavur district and it was noted that although overall the effect was satisfactory, wherever the coverage was more than $70 \%$, existence of hotspots and clustering of infection are indicative of need for good surveillance and action strategy, with evidence based sampling strategy and evaluation of unit size for Transmission Assessment Survey (TAS) (Swaminathan et al., 2012).

Drug distribution coverage, compliance and effective coverage in Burdwan district in West Bengal was found to be $48.76 \%, 70.02 \%$ and $34.16 \%$ resp. Authors concluded that there is urgent need to improve compliance with drug intake through strengthening the awareness program (Roy et al., 2013).

In an independent survey in endemic area of Gujrat it was seen that during MDA, drug coverage was $81-88 \%$, epidemiological coverage $77-89 \%$, directly observed consumption increased from $58 \%$ in 2010 to $82 \%$ in 2015. Current Mf rate was less than one in all implementation units (IUs) with $68 \%$ decrease from baseline year 2005 to year 2015 (Modi et al., 2017).

Assessment of coverage, compliance and side effects of MDA in Bankura district, West Bengal showed drug compliance rate, effective coverage to be lower in urban than rural area. Fear of side effects was the main reason for noncompliance. Reported side effects were few, mild and transient. Poor social mobilization, lack of knowledge about disease and program were major areas of concern (Ghosh et al., 2013).

Study on barriers to coverage and compliance to MDA in Odisha showed that only a quarter of the 99\% who received drugs, actually consumed DEC ABZ. Cause of noncompliance was mostly fear of side effect, lack of awareness of benefits of MDA and non-attendance of health staff (Hussain et al., 2014).

It has been observed that there was high rate of acquiring infection by children born to LF infected mothers than uninfected mothers even though $\mathrm{mf}$ rate had come down to $<1 \%$ after implementing ten round of MDA. Authors concluded that to attain target of eliminating LF, the current MDA program should give emphasis on covering the women of child bearing age 
and recommended that supervised MDA should be incorporated in Adolescent reproductive and sexual health program ARSH (Bal et al., 2015).

They also showed that maternal filarial infection influences the development of regulatory $\mathrm{T}$ cells in children from infancy to early childhood (Bal et al., 2016).

A plan of action has been discussed to use DEC fortified salt for diurnally subperiodic filariasis for Nicobar district (Shriram et al., 2015).

Some studies have investigated productivity loss due to lymphatic filariasis. Productivity loss due to lymphedema in previous 30 days was estimated to be 6.4 days (Lenk et al., 2016).

A research priority setting process has been organized as described in James Lind Alliance guidebook and it identified seven priority areas to achieve effective morbidity control of lymphedema including due to LF (Narahari et al., 2017).

\section{Pathogenesis and Diagnostic Tests}

Molecular mechanisms underlying the pathogenesis of disease and quantitative immune response patterns differentiating patients with overt from subclinical manifestation has been reviewed. This will enable design of effective pharmacological inhibitors and pathogenesis specific interventions aimed at the early stage of the disease before major lymphatic function have been chronically affected (Chakraborty et al., 2013).

The predominant immunological feature in LF is an antigen specific $T h 2$ response and a muted $T h 1$ response. This is crucial for the maintenance of the sustained, long standing infection with high parasite densities (Babu and Nutman, 2017).

Study of plasma levels of various markerscirculating microbial products such as LPS and markers associated with microbial translocation, in four groups of individuals-chronic pathology individuals with or without active filarial infection, asymptomatic filarial infected individuals and uninfected endemic normal individuals showed that circulating levels of LPS, acute phase proteins and certain cytokines are significantly elevated in filarial disease with active infection but not in other groups indicating that it is correlated with filarial lymphatic pathology (Anuradha et al., 2012).

Vishal evaluated rapid blood sample collection in the detection of circulating filarial antigen for epidemiological survey by rwbsxp-1 capture assay and showed that it gave $7.32 \%$ increased positive results (Vishal et al., 2014).

\section{Clinical Trials and Observational Studies}

The effect of higher and more frequent dosing of ABZ with fixed $300 \mathrm{mg}$ dose of DEC was studied and it was found that microfilaria decreased more rapidly with higher or more frequent dosing without any increase in ADR (Kar et al., 2015).

Britto studied in a double blind randomized control trial (RCT), 146 asymptomatic W. bancrofti infected individuals, effects of DEC $300 \mathrm{mg}+$ Doxycycline $100 \mathrm{mg}$ co-administered or DEC 300 $\mathrm{mg}+\mathrm{ABZ} 400 \mathrm{mg}$ co-administered or DEC 300 mg+ABZ $400 \mathrm{mg}$ given sequentially DEC $300 \mathrm{mg}$ $\mathrm{ABZ}$ sequential treatment had better efficacy in microfilaria clearance though effect on antigenemia was comparable (Britto et al., 2015).

Study in mf positive patients found no difference between effect of DEC $(6 \mathrm{mg} / \mathrm{kg})$ and DEC $(6 \mathrm{mg} / \mathrm{kg})$ $+\mathrm{ABZ} 400 \mathrm{mg}$ on safety and micro filaria (judged by peripheral smear and nucleopore filter method) and adult worm (judged by circulating filarial antigen card test and ultrasonography). Study consisted of three annual rounds of DEC or DEC ABZ in double blind randomized controlled trial (Kshirsagar et al., 2017 accepted). They concluded that there is not much effect on adult worm with three yearly administration of DEC or DEC ABZ. However other workers did find effect, specially when given for more than 3 rounds and in children.

Thomas compared three quality of life instruments in LF DLQI, WHO DAS 2.0, and LF SQQ. The study provides insight into use of tools and shows that LF SQQ performed best. (Thomas et al., 2014).

\section{New Drugs and Vaccines}

Researchers have studied medicinal plants, synthetic chemicals and drug delivery systems for antifilarial activity. 
Ursolic acid a major constituent of Eucalyptus tereticornis was lethal in vitro to microfilara and female adult worm of $B$. Malayi as observed by motility assay. In silico PK and drug likeness studies showed UA has drug like properties. In vivo in $B$. Malayi M coucha model (natural infection), UA showed 54\% macrofilaricidal and 56\% adult worm sterility and unchanged microfilaremia. Thus it is a promising widely available natural lead for developing macrofilaricidal drug (Kalani et al., 2014).

From ethanolic extracts of aerial parts of $T$. distichum, four molecules were isolated, structure determined. A 001 was effective in killing adult worm and microfilaria of B. Malayi in vitro in MTT assay. Diterpenoid K003 produced $100 \%$ reduction in motility of microfilaria and adult worm and $>80 \%$ inhibition in MTT reduction potential of adult female worms. In B. Malayi, M. Coucha model, K003 killed 54\% of adult worms and $36 \%$ female worm were rendered sterile (Kushwahaet al., 2016).

This indicates that labdane diterpenoid molecules may provide valuable lead to design and development of new macrofilaricidal agents.

Yadav reported antifilarial activity of diarylheptanoids from Alnus nepalensis leaves. Out of 4 compounds tested one showed antifilarial activity in vitro and in vivo studies in Host-parasite model i.e., B-Malayi-M. unguictatus model (Yadavet al., 2013).

Ultrafine PLGA nanoparticles of Doxycycline hydrochloride were constructed and it's preferential lymphatic targeting, greater in vivo antifilarial activity compared to doxycycline solution as gauged by tests in B. malayi infected M. Coucha model, were found (Singh et al., 2016).

Nanoparticles of silver, elicited significant loss in microfilarial motility (obtained from infected jird) (Singh et al., 2012).

Proteome subtractive approach was used to screen possible therapeutic targets in Wolbachia of Brugia Malayi. Authors also did literature search and presented the data in a user friendly database Filo Base (Sharma and Kumar, 2016).

The available drugs and their targets, novel targets, websources and databases were summarized to re-examine and develop new drugs using bioinformatics (Sharma et al., 2013).

Natural sources having antifilarial potential have been summarized (Mendam et al., 2015).

Mukherjee reported new metabolic targets to identify new antimetabolic drugs (Mukherjee et al., 2016).

Trehalose 6- phosphate phosphatase of Brugia malayi represents an attractive vaccine target as it is absent in mammals. Immunization with the recombinant protein caused $78 \%$ decrease in microfilaremia and $71 \%$ decrease in adult worm establishment and sterilizaiton of recovered live female (Kushwaha et al., 2013).

Vaccination in mice with trivalent HAT vaccine as HAT protein alone or as heterologous prime boost vaccine conferred significant protection (95\%) against B. Malayi L3 challenge suggesting that trivalent HAT fusion protein is a promising prophylactic vaccine against LF infection in humans (Dakshinamoorthy et al., 2013).

\section{Conclusions and the Way Forward}

To achieve the goal of elimination by 2020 mass drug administration needs to be continued for much longer duration in high transmission and high infection area. An important conclusion from the studies done has been that there is low coverage and poor compliance in some areas due to potentially correctable causes. Important causes of noncompliance were found to be fear of side effects, lack of awareness of benefits of MDA and insufficient involvement of health staff.

In the search for drugs with effect on adult worm and rapid and long lasting effect on microfilaria, doxycycline with DEC, Albendazole with DEC in different schedules were investigated. However methods to detect adult worm viz., antigenemia, ultrasound have not given consistent specificity and sensitivity.

There is need to develop biomarkers for detecting adult worm and lymphatic system pathology.

Several workers have shown promising results especially of effect on adult worm with compounds from plants. 
However further work is needed to identify most promising compounds and conduct studies, on toxicity testing and in vivo animal models, to study them further in humans.

In recent years triple drug combination of $\mathrm{DEC}+\mathrm{ABZ}+$ Ivermectin has shown very promising results and should be considered as comparator for any further studies.

Filariasis infection is noted in early childhood. Current mass drug administration program excludes children below $2 \mathrm{yr} \& 5 \mathrm{yr}$ and pregnant women. There is a great need to show safety of drugs in children and develop formulation suitable for children.

\section{Dengue}

Dengue virus belonging to family Flaviviridae having four subtypes, spread by the bite of infected Aedes mosquito, causes a wide spectrum of illness from mild asymptomatic illness to severe dengue haemorrhagic fever/dengue shock syndrome (DHF/DSS). A multinational study estimated that there were 390 million cases worldwide $1 / 3^{\text {rd }}$ in India. Of the 390 million, $1 / 4^{\text {th }}$ manifest clinically, most cases are undetected (Bhatt, 2013). Gupta et al. reviewed in 2012, work done by various groups of scientists in India focusing mainly on epidemiology, clinical presentation, experimental studies on immune response, pathogenesis and diagnosis in DV infection (Gupta et al., 2012).The manifestation of "expanded dengue" with unusual manifestations has been reviewed (Kadam et al., 2016). Work during 20122017 is reviewed below:

\section{Clinical Trials and Observational Studies}

List of dengue drug trials identified from WHO International Clinical Trials Registry platform web portal using search term "dengue" on Dec 31 ${ }^{\text {st }}, 2015$ was reviewed. None of the handful of drugs tested so far has yielded encouraging results. There is need for tools to predict "high risk" patients early on (Beesetti et al., 2016).

Immunogenicity and safety of recombinant live attenuated tetravalent dengue vaccine (CYD-TDV) given at 0,6,12 months was studied in healthy adults in India. In a randomized observer blind placebo controlled phase II trial, immunogenicity was assessed by using a $50 \%$ plaque reduction neutralization test
(PRNT50) at baseline and at-28 days after each study injection. Sero positivity rates with each serotype, increased with geometric mean titres being 2.38 to 6.11-fold higher after $3^{\text {rd }}$ injection compared to baseline. There were no serious adverse events (Dubey et al., 2016).

Reddy compared effect of furosemide with furosemide + ventilation, ventilation alone in 1 month18 years old children with ARDS with dengue IgM positivity. They found significant survival difference between groups and pre and post intervention arterial blood gases and concluded that diuretic infusion improves outcome in dengue with ARDS (Reddy et al., 2014).

Single dose of anti D $50 \mu \mathrm{g} / \mathrm{kg}$ was found to increase significantly patients $(60 \%)$ with platelet count over $50,000 / \mathrm{mm}^{3}$ compared to $6.7 \%$ in control group and reduced platelet concentrate infusion need and improvement in bleeding manifestations (Pannu et al., 2017)

A systematic review and meta-analysis of efficacy and safety of Carica Papaya leaf extract in dengue, showed that in four studies in 439 patients given Carica Papaya leaf extract, there was increase in platelet count, decrease in hospitalization days. There was no significant difference between $C$. Papaya and control group (Charan et al., 2016).

Dengue causes platelet activation and thrombocytopenia in patients.

C. Papaya leaf extract was studied to evaluate if its action is directly on platelets and if the extract can specifically inhibit the platelet aggregation during dengue viral infection in vitro. Platelet aggregation was significantly reduced when leaf extract preincubuted with dengue plasma was added to control platelet rich plasma but no such effect was seen when it was incubated with control plasma. Upon addition of leaf extract to dengue PRP and control PRP significant reduction in platelet aggregation was seen. They concluded that leaf extract has dengue specific neutralizing effect on dengue viral infected plasma that may exert a protective role on platelets (Chinnappan et al., 2016), preventing aggregation and reduction in platelets.

Sarala et al also reviewed studies done on Papaya extract, one animal study, one case report, 
three case series and two RCT, and concluded that although many lack adequate information, there is a possibility that Papaya leaf extract could be an important option for future (Sarala and Paknikar, 2014).

\section{New Drugs, Vaccines, Preclinical Studies}

Some earlier preclinical work has been reviewed (Gupta, 2012). Pre-feeding mice with trivalent chromium picolinate $(\mathrm{CrP})$ in drinking water could abolish the adverse effects of DV infection on most of the haematological parameters (srivastava et al., 2007) Hippophae rhamnoides (seabuckthorn SBT) leaf extract has been shown to have a significant anti dengue activity (Jain et al., 2008).

The development and current status of dengue vaccine was reviewed (Marimuthu and Ravinder, 2016).

Among the ten proteins (structural and nonstructural) encoded by dengue viral genome, NS2BNS3 protease is an ideal target. It is responsible for the processing of poly protein that is required for genome replication of the virus.

Different inhibitors reported against dengue proteases have been reviewed (Timiri et al., 2016).

Salidroside main bioactive compound of Rhodiola rosea was evaluated for its antiviral potential against DENV. It potently inhibited DENV infection by decreasing DENV envelope protein expression more than tenfold. It also induced expression of IFN- $\alpha$, NK cells and $\mathrm{CD} 8^{+} \mathrm{T}$ cells in human PBMCs (Sharma et al., 2016).

NS2B-NS3 protease (pro) of dengue virus (DENV) is the prime therapeutic target for the development of anti-dengue drug. Neem plant (Azadirachta indica) has shown potential antiviral activity. Dwivedi etal with molecular docking study showed that nimbin, desacetylnimbin and desacetylsalannin have good binding affinity with DENV NS2B-NS3 pro while azadirachtin and salannin had no affinity (Dwivedi et al., 2016).

Ethyl 4-(4-methylphenyl)-4-pentonoate from Vetiveria Zizanoides was also shown, to inhibit dengue NS2B-NS3 protease and prevent viral assembly in docking analysis (Lavanya et al., 2016).
In a bioassay-guided screening approach, indigenous herbals were evaluated by Sood et al. Alcoholic extract of Cissampelos pareira Linn (Cipa extract) was found to be potent inhibitor of all four DENVs in cell based assay, assessed in terms of viral NS1 antigen secretion using ELISA as well as viral replication based on plaque assay. Virus yield reduction assay showed that Cipa extract could decrease viral titres by an order of magnitude. The extract also conferred significant protection against DENV infection in AG129 mouse model. It had no adverse effects on platelet counts and RBC viability. It had antipyretic activity in wistar rats, down regulated TNF- $\alpha$ and had no toxic effect in wistar rats at doses as high as $2 \mathrm{gm} / \mathrm{kg}$ (Sood et al., 2015).

Rhodiola that significantly promoted ISG, RIGI and MDA5 gene expression and an antiviral immune response against dengue virus infection has been identified. Rhodiola induced, (IFN) $\beta$ and other cytokines in infected cells. Number of NK cells was increased in dengue virus infected human PBMCs. It can be a novel therapeutic strategy (Diwaker et al., 2014).

Mahadevan and Palraj reviewed available literature on Siddha Herbal Formulations (Kudineer) on management of dengue. Symptoms of Pitha suram described in Siddha are comparable with symptoms of dengue. Antiviral, anti-inflammatory and immune modulator pharmacological actions of ingredients of Siddha Kudineer formulations used in treatment of dengue are summarized (Mahadevan and Palraj, 2016).

Ramya evaluated effect against dengue virus of actinobacterially synthesized selenium particle. Streptomyces minutiscleroticus M 10 A 62 isolated from a magnesite mine has the ability to synthesize selenium nanoparticles (SeNPs) extracellularly. It was characterized and found to have good antiviral activity in vitro against Dengue virus (Ramya et al., 2015).

A benzimidazole derivative MB21 was found to be most potent in inhibiting the cloned protease $\left(\mathrm{IC}_{50}=\right.$ $5.95 \mu \mathrm{M})$. It also inhibited all 4 serotypes of dengue viruses in infected cells in culture, based on analysis of virus antigen synthesis and infectious virus production. It did not have any cytotoxicity (Raut $e t$ al., 2015). 
A 3D modelling of dengue virus NS4B (nonstructural protein-4B) and virtual screening of selected compound showed N-(p-tolylmethyl)-3-[(3pyridylmethylamino)methyl] benzamide (TPB) had significant binding characteristics (Satheesh et al., 2014).

$\beta-0 \mathrm{G}$ pocket a cavity in the flavivirus envelope (E) protein has been identified as a promising site for the design of antiviral agents that interfere with virus entry into the host cell.

Jadav evaluated hybrid compounds in virus cell based assay and found a molecule with an EC50 of $1.32 \pm 0.41 \mu \mathrm{M}$ against dengue virus serotype 2 (Jadav et al., 2015).

Amodiaquine inhibited DEN V2 infectivity measured by plaque assay with EC50 and EC90 values of $1.08 \pm 0.09 \mu$ Mand $2.69 \pm 0.47 \mu \mathrm{M}$ and DEN V2 RNA replication measured by Renilla luciferase reporter assay (Boonyasuppayakorn et al., 2014).

Parida selected panduratin molecule, designed 65 novel compounds, did virtual screening and docking studies for NS3 inhibitor activity by targeting proteinprotein interacting sites of dengue virus (Parida et al., 2013).

Dengue viral-dependent RNA polymerase inhibitor was identified using computational fragment based approaches and molecular dynamic study (Anusuya et al., 2016).

Synthesis and molecular modelling studies on novel sulphonamide derivatives as NS2B-NS3 protease inhibitor has been carried out (Timiri et al., 2015).

Magnetic nanoparticles inhibited at $2-8 \mu \mathrm{g} / \mathrm{ml}$ DEN-2 replication inhibiting the expression of the envelop (E) protein (Murugan et al., 2017).

\section{References}

Agrawal S, Khandelwal K, Bumb R A, Oghumu S, Salotra P and Satoskar A R (2014) Short Report: Pediatric Cutaneous Leishmaniasis in an Endemic Region in India by The American Society of Tropical Medicine and Hygiene 91 901-904

Aminake M N, Mahajan A, Kumar V, Hans R, Wiesner L, Taylor
The bioactivity of Bruguiera cylindrica synthesized characterized silver nanoparticles (AgNP) has been studied. It inhibited production of dengue viral envelope protein in vero cells and downregulated the expression of dengue viral E gene (Murugan et al., 2015).

Ag NP has been synthesized using Moringa oleifera seeds extract as reducing and stabilizing agent. It showed in vitro antiviral activity against DEN-2 infecting vero cells (Sujitha et al., 2015).

\section{Conclusions and the Way Forward}

Clinically of the 50-100 million patients infected with dengue, 500000 develop manifestation of dengue haemorrhagic and dengue shock syndrome fever. There is need to develop tests to predict these "high risk" patients.

Perusal of publication on new drug development for dengue shows that a variety of new chemicals, and plants are investigated in molecular docking studies, cell based assays and mouse model. NS2BNS3 protease of dengue virus is prime target for drug development. Alcoholic extract of Cissampelos pareira Linn is in advanced stage of development.

Dengue vaccine developed indigenously and one marketed internationally are being investigated for protective immunity. Clinical studies on dengue vaccine and promising drugs are greatly needed.

Vaccine research is indeed greatly needed for dengue control and treatment.

\section{Acknowledgement}

Miss Jaya Bajpai and Miss Shibani Supe carried out the literature search in Google Scholar and Pubmed and contributed to referencing.

D and Rethwilm A (2012) Synthesis and evaluation of hybrid drugs for a potential HIV/AIDS-malaria combination therapy Bioorganic \& Medicinal chemistry 20 5277-5289

Anuradha R, George P J, Kumar N P, Fay M P, Kumaraswami V, Nutman T B and Babu S (2012) Circulating microbial products and acute phase proteins as markers of 
pathogenesis in lymphatic filarial disease by $P L o S$ Pathogens 8 1-9

Anusuya S, Velmurugan D and Gromiha M M (2016) Identification of dengue viral RNA-dependent RNA polymerase inhibitor using computational fragment-based approaches and molecular dynamics study Journal of Biomolecular Structure and Dynamics 34 1512-1532

Anvikar A R, Arora U, Sonal G S, Mishra N, Shahi B, Savargaonkar D, Kumar N, Shah N K and Valecha N (2014) Antimalarial drug policy in India: past, present \& future Indian Journal of Medical Research 13205

Anvikar A R, Shah N, Dhariwal A C, Sonal G S, Pradhan M M, Ghosh S K, and Valecha N (2016) Epidemiology of Plasmodium vivax malaria in India The American Journal of Tropical Medicine and Hygiene 95(6 Suppl) 108-120

Anvikar A R, Sharma B, Shahi B H, Tyagi P K, Bose T K, Sharma S K, Srivastava P, Srivastava B, Kiechel J R, Dash A P and Valecha N (2012) Artesunate-amodiaquine fixed dose combination for the treatment of Plasmodium falciparum malaria in India Malaria Journal 1197

Arora N and K Banerjee A (2012) New targets, new hope: novel drug targets for curbing malaria Mini reviews in medicinal chemistry 12 210-226

Babu B V and Babu G R (2014) Coverage of, and compliance with, mass drug administration under the programme to eliminate lymphatic filariasis in India: A systematic review by Transactions of the Royal Society of Tropical Medicine and Hygiene 108 538-549

Babu S and Nutman T B (2014) Immunology of lymphatic filariasis by Parasite Immunology 36 338-346

Baharia R K, Tandon R, Sharma T, Suthar M K, Das S, Siddiqi M I and Dube A (2015) Recombinant NAD-dependent SIR2 Protein of Leishmania donovani: Immunobiochemical Characterization as a Potential Vaccine against Visceral Leishmaniasis by PLOS: Neglected tropical diseases 1-26

Bal M, Ranjit M, Achary K G and Satapathy A K (2016) Maternal Filarial Infection Influences the Development of Regulatory T Cells in Children from Infancy to Early Childhood by PLoS Neglected Tropical Disease 10 1-15

Bal M, Sahu P K, Mandal N, Satapathy A K, Ranjit M and Kar S K (2015) Maternal Infection Is a Risk Factor for Early Childhood Infection in Filariasis by PLOS Neglected Tropical Diseases 9 39-55

Beck H P, Wampfler R, Carter N, Koh G, Osorio L, Rueangweerayut R, Krudsood S, Lacerda M V, LlanosCuentas A, Duparc S, Rubio J P and Green J A (2016) Estimation of the antirelapse efficacy of tafenoquine, using Plasmodium vivax genotyping Journal of Infectious
Diseases 213 794-799

Beesetti H, Khanna N and Swaminathan S (2016) Investigational drugs in early development for treating dengue infection Expert opinion on investigational drugs 251059 1069

Belhekar M N, Advani M G, and Pawar S R (2012) A prospective study of adverse drug reactions to artemisinin-based combination therapy in a tertiary care hospital in India Indian journal of pharmacology 44257

Bhandari V, Kulshrestha A, Deep D, Stark O, Prajapati K, Ramesh V, Sundar S, Schonian G, Dujardin J and Salotra P (2012) Drug Susceptibility in Leishmania Isolates Following Miltefosine Treatment in Cases of Visceral Leishmaniasis and Post Kala-Azar Dermal Leishmaniasis by PLos Neglected tropical diseases 6 1-6

Bharati K and Ganguly N K (2013) Tackling the malaria problem in the South-East Asia Region: Need for a change in policy? Indian Journal of Medical Research 13736

Bhargava P and Singh R (2012) Developments in Diagnosis and Antileishmanial Drugs by Interdisciplinary Perspectives on Infectious Disease (2012) 1-13

Bharti P, Shukla M, Ringwald P, Krishna S, Singh P, Yadav A, Mishra S, Gahlot U, Malaiya J, Kumar A, Prasad S, Baghel P, Singh M, Vadadi J, Singh M, Bustos M, Ortega L, Christophel, Kashyotia S, Sonal G and Singh N (2016) Therapeutic efficacy of artemether-lumefantrine for the treatment of uncomplicated Plasmodium falciparum malaria from three highly malarious states in India Malaria Journal 15498

Bhatt S, Gething P W, Brady O J, Messina J P, Farlow A W, Moyes C L, Drake J M, Brownstein J S, Hoen A G, Sankoh O, Myers M F, George D B, Jaenisch T, Wint G R, Sinmmons C P, Scott T W, Farrar J J, and Hayn S I (2013) The global distribution and burden of dengue; Nature 496 504-507

Bhattacharya D, Bhuyan B M, Pradhan P K and Nayak D K (2013) Transmission Blocking of Year Round Resistant Malaria in Koraput (India) by OMARIA - A New Antimalarial Phytotherapy British Journal of pharmaceutical research 354-77

Boonyasuppayakorn S, Reichert E D, Manzano M, Nagarajan K and Padmanabhan R (2014) Amodiaquine, an antimalarial drug, inhibits dengue virus type 2 replication and infectivity Antiviral research 106 125-134

Britto R, Vanamail P, Sankari T, Vijayalakshmi G, Das L K and Pani S P (2015) Enhanced efficacy of sequential administration of Albendazole for the clearance of Wuchereriabancrofti infection: Double blind RCT Tropical 
Biomedicine 32198-209

Burza S, Sinha P K, Mahajan R, Sanz M G, Lima M A, Mitra G, Verma N and Das P (2014b) Post Kala-Azar Dermal Leishmaniasis following Treatment with $20 \mathrm{mg} / \mathrm{kg}$ Liposomal Amphotericin B (Ambisome) for Primary Visceral Leishmaniasis in Bihar PLos Neglected tropical diseases $\mathbf{8}$

Burza S, Sinha P, Mahajan R, Lima A, Mitra G, Verma N, Balasegarem M and Das P (2014c) Five-Year Field Results and Long-Term Effectiveness of $20 \mathrm{mg} / \mathrm{kg}$ Liposomal Amphotericin B (Ambisome) for Visceral Leishmaniasis in Bihar, India PLos Neglected tropical diseases 8 2-11

Burza S, Sinha P, Mahajan R, Lima A, Mitra G, Verma N, Balsegaram M and Das P (2014a) Risk Factors for Visceral Leishmaniasis Relapse in Immunocompetent Patients following Treatment with $20 \mathrm{mg} / \mathrm{kg}$ Liposomal Amphotericin B (Ambisome) in PLos Neglected tropical diseases $\mathbf{8}$

Chakraborty S, Gurusamy M, Zawieja D C and Muthuchamy M (2013) Lymphatic filariasis: Perspectives on lymphatic remodeling and contractile dysfunction in filarial disease pathogenesis Microcirculation NIH public access 20349 364

Chander M P, Pillai C R and Vijayachari P (2015) Antimalarial efficacy of nine medicinal plants traditionally used by the Karens of Andaman and Nicobar Islands, India, Bangladesh Journal of Pharmacology 11 126-129

Chander M P, Pillai C R, Sunish I P and Vijayachari P (2016) Antimicrobial and antimalarial properties of medicinal plants used by the indigenous tribes of Andaman and Nicobar Islands, India Microbial pathogenesis 96 85-88

Charan J, Saxena D, Goyal J P and Yasobant S (2016) Efficacy and safety of Carica papaya leaf extract in the dengue: A systematic review and meta-analysis International Journal of Applied and Basic Medical Research 6249

Chhajer R and Ali N (2014) Genetically modified organisms and visceral leishmaniasis Mini review article by Frontiers in immunology 5 1-10

Chinnappan S, Ramachandrappa V, Tamilarasu K, Krishnan U M, Pillai A K and Rajendiran S (2016) Inhibition of platelet aggregation by the leaf extract of Carica papaya during dengue infection: An in vitro Study Viral immunology 29 164-168

Chittoria A, Mohanty S, Jaiswal Y K and Das A (2012) Natural selection mediated association of the Duffy (FY) gene polymorphisms with Plasmodium vivax malaria in India PLoS One 7 e 45219

Dakshinamoorthy G, Samykutty A K, Munirathinam G, Reddy
M V and Kalyanasundaram R (2013) Multivalent fusion protein vaccine for lymphatic filariasis Vaccine 31 16161622

Das R, Dhiman R C, Savargaonkar D, Anvikar A R and Valecha N (2016) Genotyping of Plasmodium vivax by minisatellite marker and its application in differentiating relapse and new infection Malaria journal 15115

Das S, Ghosh S, De AK and Bera T (2017) Oral delivery of ursolic acid-loaded nanostructured lipid carrier coated with chitosan oligosaccharides: Development, characterization, in vitro and in vivo assessment for the therapy of leishmaniasis International Journal of Biological Macromolecules 102 996-1008

Das S, Rani M, Rabidas V, Pandey K, Sahoo G C and Das P (2014) TLR9 and MyD88 are crucial for the maturation and activation of dendritic cells by paromomycin miltefosine combination therapy in visceral leishmaniasis British Journal of Pharmacology 171 1260-1274

Deep D K, Singh R, Bhandari V, Verma A, Sharma V, Wajid S, Sundar S, Ramesh V, Dujardin J C, and Salotra P (2017) Increased miltefosine tolerance in clinical isolates of Leishmania donovani is associated with reduced drug accumulation, increased infectivity and resistance to oxidative stress PLOS Neglected tropical diseases 1-16

Dikhit M R, Purkait B, Ranjan B, Kumar A, Kar R K, Saini S, Kumar A, Sahoo G S, Das S, and Das P(2016) Activity of a novel sulfonamide compound against Leishmania donovani, Drug Design, Development and Therapy 2016 1753-1761

Diwaker D, Mishra K P, Ganju L and Singh S B (2014) Rhodiola inhibits dengue virus multiplication by inducing innate immune response genes RIG-I, MDA5 and ISG in human monocytes Archives of virology 1591975

Dubey AP, Agarkhedkar S, Chhatwal J, Narayan A, Ganguly S, Wartel TA, Bouckenooghe A, and Menezes J (2016) Immunogenicity and safety of a tetravalent dengue vaccine in healthy adults in India: a randomized, observer-blind, placebo-controlled phase II trial Human vaccines \& immunotherapeutics 12 512-518

Dwivedi V D, Tripathi I P and Mishra S K (2016) In silico evaluation of inhibitory potential of triterpenoids from Azadirachtaindica against therapeutic target of dengue virus, NS2B-NS3 protease Journal of vector borne diseases 53 156

Fernandes R C, Hasan M, Gupta H, Geetha K, Rai P S, Hande M H, D'Souza S C, Adhikari P, Brand A and Satyamoorthy K (2015) Host genetic variations in glutathione-S-transferases, superoxide dismutases and catalase genes influence 
susceptibility to malaria infection in an Indian population Molecular Genetics and Genomics 2901155 1168

Ganguly S, Saha P, Guha S K, Das S, Bera D K, Biswas A, Kundu P K, Saha B, Ray K and Maji A K (2013) In vivo therapeutic efficacy of chloroquine alone or in combination with primaquine against vivax malaria in Kolkata, West Bengal, India, and polymorphism in pvmdr1 and pvcrt-o genes Antimicrobial agents and chemotherapy 57 12461251

Garg M and Goyal N (2015) MAPK1 of Leishmania donovani modulates antimony susceptibility by down regulating Pglycoprotein efflux pumps Antimicrobial Agents and Chemotherapy 59 3853-3863

Gehlawat V K, Arya V, Kaushik J S and Gathwala G (2013) Clinical spectrum and treatment outcome of severe malaria caused by Plasmodium vivax in 18 children from northern India Pathogens and global health 107 210-214

Ghosh S, Samanta A and Kole S (2013) Mass drug administration for elimination of lymphatic filariasis: Recent experiences from a district of West Bengal, India Tropical Parasitology 3 67-71

Godse C S, Tathed P S, Talwalkar S S, Vaidya R A, Amonkar A J, Vaidya A B and Vaidya A D (2016) Antiparasitic and disease-modifying activity of Nyctanthesarbor-tristis Linn. in malaria: An exploratory clinical study Journal of Ayurveda and Integrative Medicine 7 238-248

Goswami R P, Goswami R P, Das S, Satpati A and Rahman M (2016) Short-Course Treatment Regimen of Indian Visceral Leishmaniasis with an Indian Liposomal Amphotericin B Preparation (Fungisome TM ) American Journal of Topical Medicine hygiene 94 93-98

Goyal M, Alam A and Bandyopadhyay U (2012) Redox regulation in malaria: current concepts and pharmacotherapeutic implications Current medicinal chemistry 19 1475-1503

Gupta H, Chaudhari S, Rai A, Bhat S, Sahu P K, Hande M H, D'Souza S C, Shashikiran U and Satyamoorthy K (2017) Genetic and epigenetic changes in host ABCB1 influences malaria susceptibility to Plasmodium falciparum PloS one $12 \mathrm{e} 0175702$

Gupta N, Srivastava S, Jain A and Chaturvedi U C (2012) Dengue in India Indian J Med Res 136 373-390

Gupta P, Anvikar A R, Valecha N and Gupta Y K (2014) Pharmacovigilance practices for better healthcare delivery: knowledge and attitude study in the national malaria control programme of India Malaria research and treatment 2014 ????
Haanshuus C G, Chandy S, Manoharan A, Vivek R, Mathai D, Xena D, Singh A, Langeland N, Blomberg B, Vasanthan G, Sitaram U, Appasamy J, Nesaraj J, Henry A, Patil S, Alvarex-Uria G, Armstrong L and Morch K (2016) A high malaria prevalence identified by PCR among patients with acute undifferentiated fever in India PLoS One 11 e0158816

Hagawane T N, Gaikwad R V, and Kshirsagar N A (2016) Dual hit lipopolysaccharide \& oleic acid combination induced rat model of acute lung injury/acute respiratory distress syndrome Indian Journal of Medical Research 143 (MAY) 624-632

Hussain M A, Sitha A K, Swain S, Kadam S and Pati S (2014) Mass drug administration for lymphatic filariasis elimination in a coastal state of India: a study on barriers to coverage and compliance by Infectious Diseases of Poverty 331

http://www.who.int/topics/tropical diseases/en/

Inbanffeson S J, Sundaram R and Suganthi P (2012) In vitro antiplasmodial effect of ethanolic extracts of traditional medicinal plant Ocimum species against Plasmodium falciparum Asian Pacific Journal of Topical Medicine 5 103106

Islamuddin M, Chouhan G, Farooque A, Dwarakanath B S, Sahal D and Afrin F (2015) Th1-Biased Immunomodulation and Therapeutic Potential of Artemisia annua in Murine Visceral Leishmaniasis PLOS, Neglected Tropical Diseases 9 ????

Islamuddin M, Chouhan G, Want M Y, Ozbak H A, Hemeg H A and Afrin F (2016) Immunotherapeutic Potential of Eugenol Emulsion in Experimental Visceral Leishmaniasis PLOS Neglected tropical diseases 1-23

Jadav S S, Kaptein S, Timiri A, De Burghgraeve T, Badavath V N, Ganesan R, Sinha B N, Neyts J, Leyssen P and Jayaprakash V (2015) Design, synthesis, optimization and antiviral activity of a class of hybrid dengue virus $E$ protein inhibitors Bioorganic \& medicinal chemistry letters $\mathbf{2 5}$ $1747-1752$

Jain M, Ganju L, Katiyal A, Padwad Y, Mishra K P, Chanda S, Karan D, Yogendra K M and Sawhney R C (2008) Effect of Hippophae rhamnoides leaf extract against Dengue virus infection in human blood-derived macrophages Phytomedicine 15 793-799

Jain V, Agrawal A and Singh N (2013) Malaria in a tertiary health care facility of Central India with special reference to severe vivax: implications for malaria control Pathogens and global health 107 299-304

Jambulingam P, Subramanian S, de Vlas S J, Vinubala C and Stolk W A (2016) Mathematical modelling of lymphatic filariasis elimination programmes in India: required duration of mass 
drug administration and post-treatment level of infection indicators Parasites \& Vectors 9501

Jha A N, Sundaravadivel P, Singh V K, Pati S S, Patra P K, Kremsner P G, Velavan T P, Singh L and Thangaraj K (2014) MBL2 variations and malaria susceptibility in Indian populations Infection and immunity 82 52-61

Jullien V, Valecha N, Srivastava B, Sharma B and Kiechel J R (2014) Population pharmacokinetics of mefloquine, administered as a fixed-dose combination of artesunatemefloquine in Indian patients for the treatment of acute uncomplicated Plasmodium falciparum malaria Malaria journal 13187

Tiwari K, Gedda M, Tiwari V, Singh S and Singh R (2017) Limitations of current therapeutic options, possible drug targets and scope of natural products in control of leishmaniasis Mini Reviews in Medicinal Chemistry 17611768

Kadam D B, Salvi S and Chandanwale A(2016) Expanded dengue $J$ Assoc Physicians India 64 59-63

Kadam P P, Gogtay N J, Karande S, Shah V and Thatte U M (2016) Evaluation of pharmacokinetics of single-dose chloroquine in malnourished children with malaria-a comparative study with normally nourished children Indian Journal of Pharmacology $\mathbf{4 8} 498$

Kalani K, Kushwaha V, Sharma P, Verma R, Srivastava M, Khan F, Murthy P and Srivastava S (2014) In vitro, in silico and in vivo studies of ursolic acid as an anti-filarial agent $P L O S$ ONE 9

Kalia S, Walter N S and Bagai U (2015) Antimalarial efficacy of Albizialebbeck (Leguminosae) against Plasmodium falciparum in vitro and $\mathrm{P}$ berghei in vivo The Indian journal of medical research 142(Suppl 1) S101

Kamaraj C, Kaushik N K, Rahuman A A, Mohanakrishnan D, Bagavan A, Elango G, Zahir A A, Santhoshkumar T, Marimuthu S, Jayaseelan C, Kirthi A V, Rajkumar G, Velayutham K and Sahal D (2012) Antimalarial activities of medicinal plants traditionally used in the villages of Dharmapuri regions of South India Journal of Ethnopharmacology 141 796-802

Kansal S, Tandon R, Verma A, Misra P, Choudhary A K, Verma R, Verma P R, Dube A and Mishra P R (2014) Coating doxorubicin-loaded nanocapsules with alginate enhances therapeutic efficacy against Leishmania in hamsters by inducing Th1-type immune responses British Journal of Pharmacology 171 4038-4050

Kar S K, Dwibedi B, Kerketa A S, Maharana A, Panda S S, Mohanty P C, Horton J and Ramachandran C P (2015) A Randomized Controlled Trial of Increased Dose and
Frequency of Albendazole with Standard Dose DEC for Treatment of Wuchereria bancrofti Microfilaremics in Odisha, India PLoS Neglected Tropical Diseases 9 1-12

Kaur S, Kaur T and Joshi J (2016) Immunogenicity and protective efficacy of DNA vaccine against visceral leishmaniasis in BALB / c mice Journal of Biomedical Research 30304 313

Krishna S, Bharti P K, Chandel H S, Ahmad A, Kumar R, Singh P P, Singh M P and Singh N (2015) Detection of mixed infections with Plasmodium spp. by PCR, India, 2014 Emerging infectious diseases 211853

Kshirsagar N A (2014a) Single-dose liposomal amphotericin B for visceral leishmaniasis Lancet Glob Health 2 e203

Kshirsagar N A (2014b) Different liposomal amphotericin B formulations for visceral leishmaniasis-Author's reply Lancet Glob Health 2 e450

Kshirsagar N A, Gogtay N J, Garg B S, Deshmukh PR, Rajgor D, Kadam V S, Thakur P A, Gupta A, Ingole N S and Lazdins H J K (2017, accepted) Efficacy and tolerability of treatment with single doses of Diethylcarbamazine (DEC) and Diethylcarbamazine (DEC) plus Albendazole (ABZ) for three consecutive years in lymphatic filariasis: A field study in India Parasitology Research

Kshirsagar N A, Gogtay N J, Moranb D, Utzc* G, Sethiad A, Sarkare* S and Vandenbrouckef P ( 2017 accepted) Treatment of adults with acute uncomplicated malaria with azithromycin and chloroquine in India, Colombia, and Suriname Research and Reports in Tropical Medicine

Kumar A, Moirangthem R, Gahlawat S K, Chandra J, Gupta P, Valecha N, Anvikar A and Singh V (2015) Emergence of sulfadoxine-pyrimethamine resistance in Indian isolates of Plasmodium falciparum in the last two decades Infection Genetics and Evolution 36 190-198

Kumar R, Guddattu V and Saravu K (2016) Therapeutic Assessment of Primaquine for Radical Cure of Plasmodium vivax Malaria at Primary and Tertiary Care Centres in Southwestern India Korean J Parasitol 54 733-742

Kumari P, Sahal D, Jain S K, Virander S and Chauhan V S (2012) Bioactivity Guided Fractionation of Leaves Extract of Nyctanthesarbortristis (Harshringar) against P falciparum PloS One 7

Kushwaha S, Singh P K, Rana A K and Misra-Bhattacharya S (2013) Immunization of Mastomys coucha with Brugia malayi Recombinant Trehalose-6-Phosphate Phosphatase Results in Significant Protection against Homologous Challenge Infection PLOS ONE 8

Kushwaha V, Saxena K, Verma R, Verma S K, Katoch D, Kumar N, Lal B, Murthy P and Singh B (2016) Antifilarial activity 
of diterpenoids from Taxodiumdistichum Parasites \& Vectors 9312

Lavanya P, Ramaiah S and Anbarasu A (2016) Ethyl 4-(4methylphenyl)-4-pentenoate from Vetiveria zizanioides Inhibits Dengue NS2B-NS3 Protease and Prevents Viral Assembly: A Computational Molecular Dynamics and Docking Study Cell biochemistry and biophysics 74337 351

Lenk E J, Redekop W K, Luyendijk M, Rijnsburger A J and Severens J L (2016) Productivity Loss Related to Neglected Tropical Diseases Eligible for Preventive Chemotherapy: A Systematic Literature Review PLoS Neglected Tropical Diseases 10 1-19

Mahadevan H and Palraj V (2016) Literature Review on Siddha Herbal Formulations (Kudineer) Available for The Management of Dengue International Journal of Pharmacology 5 90-96

Mahajan R, Das P, Isaakidis P, Sunyoto T, Sagili K D, Lima M A, Mitra G, Kumar D, Pandey K, Van geertruyden J, Boelaert M and Burza S (2015) Combination Treatment for Visceral Leishmaniasis Patients Coinfected with Human Immunodeficiency Virus in India, Combination Therapy for HIV-VL Coinfection 61 1255-1262

Marimuthu P and Ravinder J R (2016) Trends in clinical trials of dengue vaccine Perspectives in clinical research 7161

Mendam K, Kavitha B and Naik S J K (2015) Natural sources used for treatment and prevention of filariasis World Journal of Pharmacy and Pharmaceutical Sciences (WJPPS) 4 1621-1628

Mishra A, Vinayagam J, Saha S, Chowdhury S, Roychowdhury S, Jaisankar P and Majumder H (2014) Isobenzofuranone derivatives exhibit antileishmanial effect by inhibiting type II DNA topoisomerase and inducing host response Pharmacology Research Perspective 2 1-14

Mishra J, Dey A, Singh N, Somvanshi R and Singh S (2013) Evaluation of toxicity \& therapeutic efficacy of a new liposomal formulation of amphotericin B in a mouse model Indian Journal of Medical Research 137 767-776

Mishra N, Kaitholia K, Srivastava B, Shah N K, Narayan J P, Dev V, Phookan S, Anvikar A R, Rana R, Bharti R S, Sonal G S, Dhariwal AC and Valecha N (2014) Declining efficacy of artesunate plus sulphadoxine-pyrimethamine in northeastern India Malaria journal 13284

Mishra N, Prajapati S K, Kaitholia K, Bharti R S, Srivastava B, Phookan S, Anvikar A R, Dev V, Sonal G S, Dhariwal AC, White N J and Valecha N (2015) Surveillance of artemisinin resistance in Plasmodium falciparum in India using the kelch13 molecular marker Antimicrobial agents and chemotherapy $592548-2553$

Mishra N, Singh J P, Srivastava B, Arora U, Shah N K, Ghosh S K, Bhatt R M, Sharma S K, Das M K, Kumar A, Anvikar A R, Kaitholia K, Gupta R, Sonal G S, Dhariwal A C and Valecha N (2012) Monitoring antimalarial drug resistance in India via sentinel sites: outcomes and risk factors for treatment failure, 2009-2010 Bulletin of the World Health Organization 90 895-904

Modi A, Gamit S, Jesalpura B S, Kurien G and Kosambiya J K (2017) Reaching endpoints for lymphatic filariasis elimination- results from mass drug administration and nocturnal blood surveys, South Gujarat, India PLoS Neglected Tropical Diseases 11

Mukherjee S, Mukherjee N, Gayen P, Roy P and Babu S, Metabolic Inhibitors as Antiparasitic Drugs: Pharmacological Biochemical and Molecular Perspectives Bentham Science 17 1-2

Mukhopadhyay D, Dalton J E, Kaye P M and Chatterjee M (2014) Post kala-azar dermal leishmaniasis: An unresolved mystery Trends in Parasitology 30 65-74

Murugan K, Dinesh D, Paulpandi M, Althbyani AD, Subramaniam J, Madhiyazhagan P, Wang L, Suresh U, Kumar P M, Mohan J and Rajaganesh R (2015) Nanoparticles in the fight against mosquito-borne diseases: bioactivity of Bruguieracylindrica-synthesized nanoparticles against dengue virus DEN-2 (in vitro) and its mosquito vector Aedesaegypti (Diptera: Culicidae) Parasitology Research 114

Murugan K, Wei J, Alsalhi M S, Nicoletti M, Paulpandi M, Samidoss C M, Dinesh D, Chandramohan B, Paneerselvam C, Subramaniam J, Vadivalagan C, Wei H, Amuthavalli P, Jaganathan A, Devanesan S, Higuchi A, Kumar S, Aziz AT, Nataraj D, Vaseeharan B, Canale A and Benelli G (2017) Magnetic nanoparticles are highly toxic to chloroquineresistant Plasmodium falciparum, dengue virus (DEN-2), and their mosquito vectors Parasitology Rresearch 116 495-502

Nagaraj VA, Mukhi D, Sathishkumar V, Subramani PA, Ghosh S K, Pandey R R, Shetty M C and Padmanaban G (2015) Asparagine requirement in Plasmodium berghei as a target to prevent malaria transmission and liver infections Nature Communications 68775

Nagendrappa P B, Annamalai P, Naik M, Mahajan V, Mathur A, Susanta G, Gay F and Venkatasubramanian P (2017) A prospective comparative field study to evaluate the efficacy of a traditional plant-based malaria prophylaxis Journal of intercultural ethnopharmacology 636

Nair C B, Manjula J, Subramani P A, Nagendrappa P B, Manoj 
M N, Malpani S, Pullela P K, Subbarao P V, Ramamoorthy S and Ghosh S K (2016) Differential diagnosis of malaria on truelab Uno®, a portable, real-time, MicroPCR device for point-of-care applications PloS one 11 e0146961

Narahari S, Aggithaya M, Moffatt C, Ryan T, Keeley V, Vijaya B, Rajendran P, Karalam S B, Rajagopala S, Kumar N, Bose K and Sushma K (2017) Future Research Priorities for Morbidity Control of Lymphedema Indian J Dermatol 2017 Jan-Feb 62 33-40

Nayak P N, Nayak R P, Soans S T, Alva S, Ahamed Z and Kotinakanot S (2014) A study of the clinical profile and management of malaria in pediatric age group in a tertiary care hospital in Mangalore Asian Pacific Journal of Tropical Disease 4 S158-S161

Palit P, Hazra A, Maity A, Vijayan R S K, Manoharan P, Banerjee S, Mondal N, Ghoshal N, and Ali N (2012) Discovery of Safe and Orally Effective 4-Aminoquinaldine Analogues as Apoptotic Inducers with Activity against Experimental Antimicrobial Agents and Chemotherapy 56 432-445

Panda A K, Panda M, Tripathy R, Pattanaik S S, Ravindran B and Das B K (2012) Complement receptor 1 variants confer protection from severe malaria in Odisha India PloS one 7 e49420

Pannu A K, Bhalla A, Singhal M, Suri V, Shafiq N and Varma S (2017) Safety and efficacy of a single dose of Anti-D (WinRho ${ }^{\circledR}$ ) in severe thrombocytopenia secondary to dengue virus infection Indian journal of critical care medicine: peer-reviewed, official publication of Indian Society of Critical Care Medicine $\mathbf{2 1} 80$

Parida P, Yadav R N S, Sarma K and Mohan Nainwal L (2013) Design, virtual screening and docking study of novel NS3 inhibitors by targeting protein-protein interacting sites of dengue virus-a novel approach Current pharmaceutical biotechnology 14 995-1008

Pathak A, Mårtensson A, Gawariker S, Mandliya J, Sharma A, Diwan V and Ursing J (2014) Characterization of drug resistance associated genetic polymorphisms among Plasmodium falciparum field isolates in Ujjain, Madhya Pradesh, India Malaria Journal 13182

Pathak S, Rege M, Gogtay N J, Aigal U, Sharma S K, Valecha N, Bhanot G, Kshirsagar N A, and Sharma S (2012) Agedependent sex bias in clinical malarial disease in hypoendemic regions PLoS One 7 e 35592

Patra P, Guha S, Maji A, Saha P, Ganguly S, Chakraborty A, Kundu P, Sarker S and Ray K (2012) Efficacy of oral miltefosine in visceral leishmaniasis in rural West Bengal, India Indian Journal of Pharmacology 44500

Prabhu P, Suryavanshi S, Pathak S, Sharma S and Patravale V
(2016) Artemether lumefantrine nanostructured lipid carriers for oral malaria therapy: Enhanced efficacy at reduced dose and dosing frequency International Journal of Pharmaceutics $\mathbf{5 1 1}$ 473-487

Prajapati V K, Awasthi K, Yadav T P, Rai M, Srivastva N and Sundar S (2012b) An Oral Formulation of Amphotericin B Attached to Functionalized Carbon Nanotubes Is an Effective Treatment for Experimental Visceral Leishmaniasis 205 333-336

Prajapati V K, Mehrotra S, Gautam S, Rai M and Sundar S (2012a) In vitro Antileishmanial Drug Susceptibility of Clinical Isolates from Patients with Indian Visceral Leishmaniasis - Status of Newly Introduced Drugs American journal of topical medicine and hygiene $87655-$ 657

Qayum A, Arya R and Lynn A M (2016) Ethnobotanical perspective of antimalarial plants: traditional knowledge based study BMC research notes 967

Rajgor D D, Gogtay N J, Kadam V S, Kocharekar M M, Parulekar M S, Dalvi S S, Vaidya A B and Kshirsagar N A (2014) Antirelapse efficacy of various primaquine regimens for Plasmodium vivax Malaria Research and Treatment 2014

Ramaiah K D and Ottesen E A (2014) Progress and Impact of 13 Years of the Global Programme to Eliminate Lymphatic Filariasis on Reducing the Burden of Filarial Disease PLOS Neglected tropical diseases $\mathbf{8}$

Ramesh V, Kaushal H, Mishra A K, Singh R, and Salotra P(2015a) Clinico-epidemiological analysis of Post kala-azar dermal leishmaniasis (PKDL) cases in India over last two decades: a hospital based retrospective study BMC Public Health 151092

Ramesh V, Singh R, Avishek K, Verma A, Deep D, Verma S and Salotra P (2015b) Decline in Clinical Efficacy of Oral Miltefosine in Treatment of Post Kala-azar Dermal Leishmaniasis (PKDL) in India PLOS Neglected tropical diseases 1-12

Ramya S, Shanmugasundaram T and Balagurunathan R (2015) Biomedical potential of actinobacterially synthesized selenium nanoparticles with special reference to antibiofilm, anti-oxidant, wound healing, cytotoxic and antiviral activities Journal of Trace Elements in Medicine and Biology 32 30-39

Raut R, Beesetti H, Tyagi P, Khanna I, Jain S K, Jeankumar V U, Yogeeswari P, Sriram D and Swaminathan S (2015) A small molecule inhibitor of dengue virus type 2 protease inhibits the replication of all four dengue virus serotypes in cell culture Virology Journal 1216

Reddy K R, Basavaraja G V and Shivnanda (2014) Furosemide 
infusion in children with dengue fever and hypoxemia Indian paediatrics $\mathbf{5 1} 303-5$

Roy M, Bouma M J, Ionides E L, Dhiman R C and Pascual M (2013) The potential elimination of Plasmodium vivax malaria by relapse treatment: Insights from a transmission model and surveillance data from NW India PLoSNegl Trop Dis 7 e1979

Roy R N, Sarkar A P, Misra R, Chakroborty A, Mondal T K and Bag K (2013) Coverage and awareness of and compliance with mass drug administration for elimination of lymphatic filariasis in Burdwan district, West Bengal, India Journal of Health, Population and Nutrition 31 171-177

Ramaiah K D and Ottesen E A (2014) Progress and Impact of 13 Years of the Global Programme to Eliminate Lymphatic Filariasis on Reducing the Burden of Filarial Disease 8

Saha P, Guha S K, Das S, Mullick S, Ganguly S, Biswas A, Bera D K, Chattopadhyay G, Das M, Kundu P K, Ray K and Maji A (2012) Comparative efficacy of Artemisinin Combination Therapies (ACTs) in P. falciparum malaria and polymorphism of PfATPase6, Pfcrt, Pfdhfr and Pfdhps genes in tea gardens of Jalpaiguri district, India Antimicrobial Agents and Chemotherapy AAC-05388

Sahu P K, Satpathi S, Behera P K, Mishra S K, Mohanty S and Wassmer S C (2015) Pathogenesis of cerebral malaria: new diagnostic tools, biomarkers, and therapeutic approaches Frontiers in Cellular and Infection Microbiology 5

Sahu S S, Gunasekaran K and Jambulingam P (2015) Field performance of malaria rapid diagnostic test for the detection of Plasmodium falciparum infection in Odisha State, India The Indian Journal of Medical Research 142(Suppl 1) S52

Sarala N and Paknikar S S (2014) Papaya extract to treat dengue: a novel therapeutic option? Annals of Medical and Health Sciences Research 4 320-324

Saravu K, Kumar R, Ashok H, Kundapura P, Kamath V, Kamath A and Mukhopadhyay C (2016) Therapeutic assessment of chloroquine-primaquine combined regimen in adult cohort of Plasmodium vivax malaria from primary care centres in southwestern India. PLoS One 11 e0157666

Satheesh G P, Prabhu N and Venkataramana M (2014) 3D Modeling of dengue virus NS4B and Chikungunya virus nsP4: identification of a common drug target and designing a single antiviral inhibitor Current computer-aided drug design 10 361-373

Shafi S, Afrin F, Islamuddin M, Chouhan G, Ali I, Naaz F, Sharma $\mathrm{K}$ and Zaman M (2016) â - Nitrostyrenes as Potential Anti-leishmanial Agents Frontiers in Microbiology 7 1-16
Shafiq N, Rajagopalan S, Kushwaha H N, Mittal N, Chandurkar N, Bhalla A, Kaur S, Pandhi P, Puri G, Achuthan S, Pareek A, Singh S, Srivastava J, Gaur P and Malhotra S (2014) Single Ascending Dose Safety and Pharmacokinetics of CDRI-97/78: First-in-Human Study of a Novel Antimalarial Drug Malaria Research Treatment 2014 (Fig. 1) 372521

Shah N K, Dhillon G P, Dash A P, Arora U, Meshnick S R and Valecha N (2011) Antimalarial drug resistance of Plasmodium falciparum in India: changes over time and space The Lancet Infectious Diseases 11 57-64

Shah N K, Poole C, MacDonald P D, Srivastava B, Schapira A, Juliano J J, Anvikar A, Meshnick S R, Valecha N and Mishra N (2013) Epidemiology of Plasmodium falciparum gametocytemia in India: Prevalence, age structure, risk factors and the role of a predictive score for detection Tropical Medicine \& International Health 18 800809

Sharma D, Lather M, Mallick P K, Adak T, Dang A S, Valecha N and Singh O P (2015) Polymorphism in drug resistance genes dihydrofolate reductase and dihydropteroate synthase in Plasmodium falciparum in some states of India Parasites \& vectors 8471

Sharma N, Mishra K P and Ganju L (2016) Salidroside exhibits anti-dengue virus activity by upregulating host innate immune factors Archives of virology 161 3331-3344

Sharma O P and Kumar M S (2016) Essential proteins and possible therapeutic targets of Wolbachiaendosymbiont and development of FiloBase-a comprehensive drug target database for Lymphatic filariasis Scientific Reports 619842

Sharma O P, Vadlamudi Y, Kota A G, Sinha V K and Kumar M S (2013) Drug targets for lymphatic filariasis: A bioinformatics approach (September) 155-162

Sharma R K, Thakor H G, Saha K B, Sonal G S, Dhariwal A C and Singh N (2015) Malaria situation in India with special reference to tribal areas Indian Journal of Medical Research 141537

Shivahare R, Vishwakarma P, Parmar N, Yadav P K, Haq W, Srivastava M, Gupta S and Kar S (2014) Combination of Liposomal CpGOligodeoxynucleotide 2006 and Miltefosine Induces Strong Cell-Mediated Immunity during Experimental Visceral Leishmaniasis PLOS Neglected Tropical Diseases 9 1-12

Shriram A N, Krishnamoorthy K and Vijayachari P (2015) Diurnally sub periodic filariasis among the Nicobarese of Nicobar district - Epidemiology, vector dynamics \& prospects of elimination Indian Journal of Medical Research 141(May) 598-607 
Shrivastava R, Nagar R, Ravishankar G A, Upreti R K and Chaturvedi U C (2007) Effect of pretreatment with chromium picolinate on haematological parameters during dengue virus infection in mice Indian Journal of Medical Research 126440

Singh D, Pandey K, Nand V, Das R, Das S, Verma N, Ranjan A, Lal S, Topno K, Singh S, Verma R, Kumar A, Sardar A, Purkait and Das P (2013) Evaluation of rK-39 Strip Test Using Urine for Diagnosis of Visceral Leishmaniasis in an Endemic Region of India American journal of topical medicines and hygiene 88 222-226

Singh J, Purohit B, Desai A, Savardekar L, Shanbag P and Kshirsagar N (2013) Clinical Manifestations, treatment, and outcome of hospitalized patients with Plasmodium vivax malaria in two Indian States: A Retrospective Study Malaria Research and Treatment 2013

Singh N, Bharti P K, Singh M P, Mishra S, Shukla M M, Sharma R K and Singh R K (2013) Comparative evaluation of bivalent malaria rapid diagnostic tests versus traditional methods in field with special reference to heat stability testing in central India PLoS One $\mathbf{8}$

Singh N, Chatterjee M and Sundar S (2014) The overexpression of genes of thiol metabolism contribute to drug resistance in clinical isolates of visceral leishmaniasis (kalaazar) in India Parasites \& Vectors 1-11

Singh N, Kumar M and Singh R K (2012) Leishmaniasis: Current status of available drugs and new potential drug targets Asian Pacific Journal of Tropical Medicine 5 485-497

Singh O P and Sundar S (2015) Developments in Diagnosis of Visceral Leishmaniasis in the Elimination Era Journal of Parasitology Research 2015 1-10

Singh S K, Goswami K, Sharma R D, Reddy M V R and Dash D (2012) Novel microfilaricidal activity of nanosilver International Journal of Nanomedicine 7 1023-1030

Singh Y, Srinivas A, Gangwar M, Meher J G, Misra-Bhattacharya S and Chourasia M K (2016) Subcutaneously Administered Ultrafine PLGA Nanoparticles Containing Doxycycline Hydrochloride Target Lymphatic Filarial Parasites Molecular Pharmaceutics 13 2084-2094

Sinha R, Roychoudhury J, Palit P and Ali N (2015) Cationic Liposomal Sodium Stibogluconate (SSG), a Potent Therapeutic Tool for Treatment of Infection by SSGSensitive and -Resistant Leishmania donovani Antimicrobial Agents and Chemotherapy 59 344-355

Sood R, Raut R, Tyagi P, Pareek P K, Barman T K, Singhal S, Shirumalla R K, Kanoje V, Subbarayan R, Rajerethinam R, Sharma N, Kanaujia A, Shukla G, Gupta Y K, Katiyar C K, Bhatnagar P K, Upadhyay D J, Swaminathan S and
Khanna N (2015) Cissampelospareira Linn: Natural source of potent antiviral activity against all four dengue virus serotypes PLoS Neglected Tropical Diseases 9 e0004255

Srivastava S, Mishra J, Gupta A K, Singh A, Shankar P and Singh S (2017) Laboratory confirmed miltefosine resistant cases of visceral leishmaniasis from India Parasites \& Vectors $20171-11$

Srivastava S, Shankar P, Mishra J and Singh S (2016) Possibilities and challenges for developing a successful vaccine for leishmaniasis Parasites \& Vectors 1-15

Sudarshan M, Singh T, Singh A K, Chourasia A, Singh B, Wilson M, Chakravarty J and Sundar S (2014) Quantitative PCR in Epidemiology for Early Detection of Visceral Leishmaniasis Cases in India PLoS Neglected Tropical Diseases 8 8-13

Sujitha V, Murugan K, Paulpandi M, Panneerselvam C, Suresh U, Roni M, Nicoletti M, Higuchi A, Madhiyazhagan P, Subramaniam J, Dinesh D, Vadivalagan C, Chandramohan B, Alarfaj AA, Munusamy M A, Barnard D R and Benelli G (2015) Green-synthesized silver nanoparticles as a novel control tool against dengue virus (DEN-2) and its primary vector Aedesaegypti Parasitology research $\mathbf{1 1 4}$

Sundar S, Singh A and Singh O P (2014) Strategies to Overcome Antileishmanial Drugs Unresponsiveness Journal of Tropical Medicine 2014 1-7

Sundar S, Singh A, Rai M, Prajapati V K, Singh A K, Ostyn B, Boelaert M, Dujardin J and Chakravarty J (2012) Efficacy of Miltefosine in the Treatment of Visceral Leishmaniasis in India After a Decade of Use Miltefosine for Leishmaniasis CID 55 543-550

Swaminathan S, Perumal V, Adinarayanan S, Kaliannagounder K, Rengachari R and Purushothaman J (2012) Epidemiological Assessment of Eight Rounds of Mass Drug Administration for Lymphatic Filariasis in India: Implications for Monitoring and Evaluation PLoS Neglected Tropical Diseases6

Thomas C, Narahari S R, Bose K S, Vivekananda K, Nwe S, West D P, Kwasny M and Kundu R V (2014) Comparison of Three Quality of Life Instruments in Lymphatic Filariasis: DLQI, WHODAS 2.0, and LFSQQ PLoS Neglected Tropical Diseases 8 19-21

Timiri A K, Selvarasu S, Kesherwani M, Vijayan V, Sinha B N, Devadasan V and Jayaprakash V (2015) Synthesis and molecular modelling studies of novel sulphonamide derivatives as dengue virus 2 protease inhibitors Bioorganic chemistry 62 74-82

Timiri A K, Sinha B N and Jayaprakash V (2016) Progress and prospects on DENV protease inhibitors European Journal 
of Medicinal Chemistry 117 125-143

Toure O A, Rulisa S, Anvikar A R, Rao B S, Mishra P, Jalali R K, Arora S, Roy A, Saha N, Iyer S S, Sharma P and Valecha N (2015) Efficacy and safety of fixed dose combination of arterolane maleate and piperaquine phosphate dispersible tablets in paediatric patients with acute uncomplicated Plasmodium falciparum malaria: a phase II, multicentric, open-label study Malaria journal 14469

Toure O A, Valecha N, Tshefu A K, Thompson R, Krudsood S, Gaye O, Rao B H K, Sagara I, Bose T K, Mohanty S, Rao B S, Anvikar A R, Mwapasa V, Noedl H, Arora S, Roy A, Iyer S S, Sharma P, Saha N, Jalali RK; AM-PQP Study Team, Tiacoh L, Enosse S, Tangpukdee N, Kokolomami J, Ndiaye J L, Rao D, Yumva N N, Sidibe B, Mohanty R, Jha A C, Nyirenda M, Starzengruber P and Swoboda P (2016) A Phase 3, double-blind, randomized study of arterolane maleate-piperaquine phosphate vsartemetherlumefantrine for falciparum malaria in adolescent and adult patients in Asia and Africa Clinical Infectious Diseases 62 964-971

Vaish M, Sharma S, Chakravarty J and Sundar S (2012) Evaluation of Two Novel Rapid rKE16 Antigen-Based Tests for Diagnosis of Visceral Leishmaniasis in India Journal of Clinical Microbiology 50 3091-3092

Valecha N, Mohanty S, Srivastava P, Sharma S, Tyagi P, Bergqvist Y and Ringwald P (2012) Efficacy of artemetherlumefantrine in area of high malaria endemicity in India and its correlation with blood concentration of lumefantrine The American journal of tropical medicine and hygiene 86 395-397
Valecha N, Savargaonkar D, Srivastava B, Rao B K, Tripathi S K, Gogtay N, Kochar S K, Kumar N B, Rajadhyaksha G C, Lakhani J D, Solanki B B, Jalali R K, Arora S, Roy A, Saha N, Iyer S S, Sharma P and Anvikar A R (2016) Comparison of the safety and efficacy of fixed-dose combination of arterolane maleate and piperaquine phosphate with chloroquine in acute, uncomplicated Plasmodium vivax malaria: a phase III, multicentric, open-label study Malaria journal 1542

Vishal L, Nazeer Y, Ravishankaran R, Mahalakshmi N and Kaliraj P (2014) Evaluation of rapid blood sample collection in the detection of circulating filarial antigens for epidemiological survey by rWbSXP-1 capture assay $\mathrm{PloS}$ One 9 e 102260

Want M Y, Islammudin M, Chouhan G, Ozbak H A, Hemeg H A, Chattopadhyay A P and Afrin F (2017) Nano liposomal artemisinin for the treatment of murine visceral leishmaniasis International Journal of Nanomedicine $\mathbf{2 0 1 7}$ 2189-2204

Yadav D, Singh S C, Verma R K, Saxena K, Verma R, Murthy PK and Gupta M M (2013) Antifilarial diarylheptanoids from Alnusnepalensis leaves growing in high altitude areas of Uttarakhand, India Phytomedicine 20 124-132

Zeeshan M, Alam M T, Vinayak S, Bora H, Tyagi R K, Alam M S, Choudhary V, Mittra P, Lumb V, Bharti P K, Udhayakumar V, Singh N, Jain V, Singh P and Sharma Y (2012) Genetic variation in the Plasmodium falciparum circumsporozoite protein in India and its relevance to RTS, S malaria vaccine PLoS One 7 e 43430. 